\title{
An Update on Microrna's and Metabolic Regulation with Future Therapeutic Potentials Regarding Diagnosis and Treatment of Obesity, Metabolic Syndrome and Other Related Disorders
}

Kulvinder Kochar Kaur*, Gautam Nand Allahbadia and Mandeep Singh

Dr Kulvinder Kaur Centre for Human Reproduction, Jalandhar, Punjab, India

\section{Introduction}

Micro RNAs is a family of highly conserved, single stranded 1923 nucleotide long noncoding endogenous RNAs which negatively regulate gene expression, either by inhibiting translation or by degrading largest mRNAs [1]. Over 2000 unique miRNAs have been identified in humans [2] The miRNAs are initially transcribed as long RNA precursors termed primary miRNAs (pri-miRNAs) that require the RNAse III enzyme Drosha in the nucleus to trim them into premiRNAs The premiRNAs are characterized by a stemloop or hairpin structure of 70-100 nucleotides and are exported to the cytoplasm by the nuclear export factor exportin 5 . The pre-miRNAs are subsequently cropped to become mature miRNA by another RNAse enzyme Dicer in the cytoplasm [3]. Although our understanding of the specific roles of miRNAs in cellular function is only beginning, recent studies revealed that miRNAs play a pivotal role in the most critical biological events such as development, proliferation, differentiation, apoptosis, transductionand carcinogenesis [4]. The mature miRNA's are conserved about 2 nucleotides noncoding RNAs that anneal to inexactly complementary sequences in the 3'untranslated regions(3'UTR) of target mRNA of protein coding genes, resulting in silencing of the target gene.While the mechanism of action of miRNAs is yet to be fully understood, the widely known mode of gene regulation by miRNAs occurs at the post transcriptional level by either specific inhibition of translation or induction of mRNACleavage $[5,6]$, resulting in a reduction in protein levels of their targets (Figure1) [7]. Alternatively, if the expression of miRNA's is inhibited, then increased protein expression may be seen in animal species. miRNAs are also capable of modifying chromatin (Figure1) [6]. dsRNA miRNA complex which is composed of the mature miR and its passenger strand (miR") is unwound by helicase activities of the Argonaute (Ago) multiprotein complex, globally known as the RNA-induced silencing complex (RISC) [8-10]. Determination of the active (guide) strandis based upon simple energetics between strands at the 5' ends of the dsRNA complex [11]. The preferred guide strand is subsequently incorporated into the RISC complex by directly binding to the key component of Ago [12]. miRNA target sites generally occur within the reading frame of and in 5' UTR [13]. We can regulate cancer, obesity and viral induced diseases by using miR. Further work is going on in developing of potential RNAi (miRNAand siRNA) molecules to get insights for the chemical synthesis of antiviral RNA molecule for the treatment of middle east respiratory syndrome (MERS) corona virus (CV), at genomic level [14], or development of antiviral RNA molecule for the treatment of Merkel cell polymyxoma virus (MCV) which causes $80 \%$ Merkel cell carcinomas (MCC), for T antigen silencing at genome level [15]. Similarly in HSV-1, siRNA were designed against ICP22 (US1) gene (intermediate gene) responsible for genomic replication of HSV. This approach may help us in synthesizing antiviral RNA molecules for treatment of HSV-1, at genomic level [16]. Zhou et al. have further reviewed the role of nanoparticle based delivery of RNA interference (RNAi) therapeutics [17] along with different delivery systems for various cancers e.g. role of (ALN-VSP), a lipid formation delivering
siRNAs against two important cancer genes, kinesin spindle protein (KSP) and vascular endothelial growth factor (VEGF), for the treatment of liver cancers in phase 1 trials [18]. Further doxorubicin combined with polyethylenimine (PEI) along with Pin X1-si RNA is delivered to knockout PIN2 interacting protein (PINX1) gene in C6 glioma cells. $\mathrm{Pin} \mathrm{X} 1$ is anucleolar protein associated with telomere and telomerase. Thus Pin X1-siRNA-mPEG (monomethoxy poly ethyleneglycol)-PEIsuper paramagnetic ironoxide nanoparticles (SPION) in combination with doxorubicin maybe a more effective treatment of gliomas with negligible side effects [19]. Similarly ScFv decorated Poly ethylene glycol (PEG)-block poly D,L-Lactide (PLA)-based nanoparticles show greater potential for targeted RNAi therapy of Her2(+) breast cancer [20].

The incidence of obesity defined as BMI $\geq 30 \mathrm{~kg} / \mathrm{m}^{2}$ increased dramatically worldwide during recent decades. Obesity associated with a cluster of metabolic disorders including risk of T2DM, hypertension, dyslipidemia, atherosclerosis, cardiovascular diseases and obesity per se constitute a series of threat known as metabolic syndrome [21]. This review aims to emphasize the role and recent advances of miR's in the aetiopathogenesis of obesity only and how further it can be utilized in prevention and management of obesity and its associated complications like atherosclerosis, IR, and other components of the MS.

miRNAs in Adipose Tissue, Insulin Resistance (IR), Obesity and Diabetes

\section{Aetiopathogenesis of obesity}

Adipose tissue $\{\mathrm{AT}\}$ is increasingly being recognized as a key regulator of whole body energy homeostasis and consequently as a prime therapeutic target for metabolic syndrome (MS). A substantial continuing growing body of evidence supports the concept that chronic low grade inflammation is a central characteristic of obesity contributing to development of insulin resistance $\{\mathrm{IR}\}$ in AT and other target organs including muscle,liver and the vasculature [22-24].

miRNAs in WAT differentiation: Adipocyte differentiation occurs in several stages, involving several many signaling pathways and this progress depends on various stimuli like nutrients and hormones. The mostimportant of this cascade of transcription factors

${ }^{*}$ Corresponding author: Kulvinder Kochar Kaur, Dr Kulvinder Kaur Centre for Human Reproduction Jalandhar, Punjab, India, Tel: 91-181-4613422; E-mail: kulvinder.dr@gmail.com

Received January 28, 2015; Accepted March 19, 2015; Published March 26 2015

Citation: Kaur KK, Allahbadia GN, Singh M (2015) An Update on Microrna's and Metabolic Regulation with Future Therapeutic PotentialsRegarding Diagnosis and Treatment of Obesity, Metabolic Syndrome and Other Related Disorders. J Health Med Informat 6: 184. doi:10.4172/2157-7420.1000184

Copyright: ( 2015 Kaur KK, et al. This is an open-access article distributed under the terms of the Creative Commons Attribution License, which permits unrestricted use, distribution, and reproduction in any medium, provided the original author and source are credited. 
Citation: Kaur KK, Allahbadia GN, Singh M (2015) An Update on Microrna's and Metabolic Regulation with Future Therapeutic PotentialsRegarding Diagnosis and Treatment of Obesity, Metabolic Syndrome and Other Related Disorders. J Health Med Informat 6: 184. doi: 10.4172/2157-7420.1000184

controlling adipogenesis tightly is CCAAT/enhancer binding protein $\{\mathrm{C} / \mathrm{EBP}\}$ and peroxisome proliferator activated receptor $\gamma\{\mathrm{PPAR} \gamma\}$. Besides these several signaling molecules including wingless and INT 1 proteins $\{w n t\}$ and insulin modulate adipogenesis [25,26]. Adipogenic markergenes, such as CCAAT/enhancer binding protein a (Cebpa), peroxisome proliferator activated receptor $\gamma$ (Pparg), adipocyte fatty acid binding protein (Ap2), fatty acid synthase (Fas), are regarded as the essential transcriptional regulators of preadipocyte differentiation and lipid storage in mature adipocytes. Canonical Wnt $/ \beta$ catenin signaling is recognized as a negative molecular switch during adipogenesis. Chen et al. found miR-135a-5p is markedly downregulated during the process of $3 \mathrm{~T} 3 \mathrm{~L} 1$ preadipoyte differentiation. Overexpression of miR135a-5p impairs the expression of adipogenic marker genes as well as lipid droplet accumulation and adipogenesis. Further studies show that miR135a-5p directly targets adenomatous polyposis coli (Apc), contributes to the translocation of $\beta$-Cateninfrom cytoplasm to the nucleus, and then activates the expression of Cyclin D1 (Ccnd1) and Cmyc, indicating the induction of canonical $\mathrm{Wnt} / \beta$-catenin signaling. In addition, inhibition of APC and siRNA exhibits the same effects as overexpression of miR135a-5p. Thus concluding that miR135-a$5 \mathrm{p}$ suppresses $3 \mathrm{~T}-\mathrm{L} 1$ preadipocyte differentiation and adipogenesis through the activation of canonial $\mathrm{Wnt} / \beta$-Cateninn signaling by directly targeting Apc, giving profound insight into adipogenesis and development of adipose tissue [27]. Yang et al. demonstrated that the levels miR 1908 increases during adipogenesis of human multipotent adipose derived stem cells (hADAMS) and human visceral preadipocytes. Over expression of miR1908 in hADAMS cells inhibited adipogenic differentiation and increased cell proliferation, suggesting that miR1908 is involved in the regulation of adipocyte cell differentiation and metabolism and thus may have an effect on human obesity [28].

MiR in brown adipocyte differentiation: Thermogenic adipocytes are distinct from white adipocytes in that they have more mitochondria, and in that uncoupling protein 1 (UCP1) is highly enriched in these mitochondria. UCP1 uncouples substrate oxidation from ATP production so that heat is generated instead [29]. In addition to thermogenic brown adipocytes which are located in BAT upon cold exposure, UCP1 - expressing thermogenic adipocytes can be recruited in WAT, so called brite (brown in white) or beige adipocytes resulting in WAT browning [30-33]. Thermogenic adipocytes have a substantial impact on the energy balance, as UCP1promoted heat production-nonshivering thermogenesis-is a highly energy dissipating processs $[34,35]$. Recruitment and activation of thermogenic adipocytes i.e. increasing combustion in the adipose organ by nonshivering thermogenesis, might contribute to antiobesity strategies [36]. Karbeiner et al. [37] explored the function of miRNAs in brown and white adipose tissues, which could result in novel therapeutic approaches to treat obesity in humans but as most miR's in the context have been characterized solely in mice there is a great demand for human studies [37]. Further he reviewed the roles of miR 155 and 27 in being negative regulators of brite and brown adipocyte differentiation. miR 155 prevented adipocyte differentiation in murine brown adipocytes via targeting $\mathrm{C} / \mathrm{ebp} \beta$-which in turn suppressed transcription of miR155 [38]. Mice overexpressing miR155 exhibited smaller BAT depots, as well as UCP1 in the tissue along with decreased BAT derived thermogenesis. But because of its profound effects on haematopoietic system the possible beneficial metabolic effects of miR155 antagonism might be paralleled by detrimental effects on immune responses. Although miR27 basically was identified with white adipogenesis, inhibition of miR27a/b led to a marked increae of Prdm 16, Ppara, and peroxisome proliferator activated receptor $\gamma$ coactivator $1 \alpha(\operatorname{Pgc} 1 \alpha)$, mRNA, UCP1 proteinand respiratory capacity [39]. Besides four important transcriptional regulators of the brown gene expression programme, Prdm, Ppara, cAMP responsive element bnding protein 1 (Creb1) and Pgc $1 \beta$-were validated as direct targets of the miR27 family, which revealed a direct molecular link of these miR's to the core protein network governing the development of thermogenic adipocytes. miR 106b-93 was considered a negative regulator of brown adipocyte differentiation-while miR17-92 were found to promote white adipocyte differentiation of 3TL1 preadipocytes, Wu et al. described a negative effect of miR106b and miR 93 on brown adipogenesis [40]. While miR26a/b induced and promoted human brite adipocyte differentiation, mechanistically the combination of transcriptomics, an RNAi screen and reporter assays revealed that the effects of miR26a/b are largely mediated via its target ADAM metallo peptidase17 (ADAM17/TACE), a gene that was previously described to negatively regulate nonshivering thermogenesis $[41,42]$.

Role of PPARy: Further PPAR $\gamma$ has been shown to be the major driver of the accumulation of phenotype of AT T reg cell. This was in keeping with that PPAR $\gamma$ expression by VAT Treg cells was necessary for complex restoration of insulin sensitivity in obese mice by the thiazolidenedone drug pioglitazone [43]. Ortega et al. [44] have found that transducin like enhancer split 3 (TLE3) in AT is increased in situations characterized by decreased PPAR $\gamma$ gene expression, like type 2 diabetes mellitus (T2DM) and suggest TLE3 maybe a homeostatic linchpin in IR and defective PPAR- $\gamma$ [44]. It has been reported that both miR 27a and miR 130a suppress adipocyte differentiation through PPAR $\gamma$ downregulation $[45,46]$. In 3T3-L1 cells, the levels of miR27a and miR130a are gradually decreased during adipogenesis, which is inversely correlated with the expression levels of PPAR $\gamma$. Furthermore overexpression of miR27a and miR130a evidently suppresses adipocyte differentiation, concomitant with PPAR $\gamma$ protein expression. Thus these 2 miR's negatively regulate PPAR $\gamma$ expression $[26,45,46]$.

\section{Obesity in Infancy and Early Childhood}

\section{Both allergy and obesity development have been traced back to accelerated growth early in life}

The nutrient sensitive kinase mTORC 1 is the master regulator of cell growth which is predominantly activated by amino acids. In contrast to breastfeeding, artificial infant formula feeding bears the risk of uncontrolled excessive protein intake overactivating the infant's mTORC 1 signaling pathways. Over activated mTORC1 enhances S-6-K-1 mediated adipocyte differentiation, but negatively regulates growth and differentiation of Fox P3 regulatory T cells $\{$ Treg $\}$ which are deficient in atopic individuals. Thus the 'early protein hypothesis' not only explains the mTORC1 mediated increased infant growth but also the development of mTORC1 driven diseases such as allergy and obesity due to a postnatal deviation from the appropriate mTORC1 axis driven metabolic and immunologic programming. Intake of fresh unpasteurized cow's milk exhibit an allergy preventive effect in farm children associated with increased Fox3+ Treg cell numbers. Human and bovine milk contain a substantial amouns of exosomal miRNA's which have been postulated to be involved in postnatal immune regulation [47-50]. Milk miRNA's are transported by membranous vesicles called exosomes which play a pivotal role for horizontal miRNA transfer [50]. Unidirectional transfer of miRNA loaded exosome from Tcell to antigen presenting cells (APC) has recently been confirmed. Human and bovine milk contain high amounts of exosomal miRNA155 [48,49,51,52]. Admyra et al. [50] showed that incubation of human peripheral mononuclear cells with which isolated human 
Citation: Kaur KK, Allahbadia GN, Singh M (2015) An Update on Microrna's and Metabolic Regulation with Future Therapeutic PotentialsRegarding Diagnosis and Treatment of Obesity, Metabolic Syndrome and Other Related Disorders. J Health Med Informat 6: 184. doi: 10.4172/2157-7420.1000184

milk exosomes increased the number of CD4+CD25+FoxP3+Treg cells in a dose dependent fashion. It has been shown that the ancient immune regulatory miRNA155 is required for the development of Treg cells [53]. miRNA 155 deficient mice have a reduced number of Treg cells both in thymus and in the periphery [54]. FoxP3 binding to the promoter of bic, the gene which encodes miRNA155 [54-56]. $\mathrm{T}$ cell receptor $\{\mathrm{TCR}\}$ and notch signaling upregulates IL-2Ra chain $\{C D 25\}$ rendering thymocytes receptive to subsequent cytokine signals that foster their Treg as determined into fully functional FoxP3+Treg [57-60]. IL-2 is capable of trasducing signals in CD4+Fox P3+Treg as determined by phosphorylation of signal trasducer and activator of transcription5 \{STAT5\} [60]. Deletion of miRNA155 results in limited IL-2/STAT5 signalling, which reduced Treg numbers [61]. Thus miR 155 is an important negative regulator of IL-2R/STAT5 signalling by which it enhances FoxP3 expression [61,62].

\section{Obesity in childhood}

Landgraf et al. 2015 showed that anIncrease in adipocyte size and number occurred, examining 171 AT samples in early childhood obese vs lean children (0-18yrs) where decreased basal lipolytic activity and significantly enhanced stromal vascular cell proliferation in vitro, potentially explained the AT cell hypertrophy andhyperplasia seen in obese children respectively. Macrophage infiltration underlying the formation of crown like structuers $\{$ CLS $\}$ was increased in AT of obese children from 6yrs associated with higher hsCRP serum levels along with IR [63]. With the idea to define the circulating miRNAs in childhood obesity, genome wide circulating miRNA profile was assessed by RTPCR in 10 boys ( 5 lean and 5 obese children) and further most relevant miRNAs were cross validated in 85 lean vs 40 obese children and longitudinally evaluated in samples from same children when they were 7 and 10yrs old. 15specific miRNAs were significantly deregulated in prepubertal obesity including the decreased miR 221 and miR28$3 p$ and increased concentration in plasma of miR486-5p, 486-3p, miR $142-3 p, m i R 130 b$ and miR423-5b .The circulating concentrations of these miRNAs was significantly associated with BMI, HOMA-IR and high molecular weight adiponectin, CRP and circulating lipids in concordance with anthropometric associations. Plasma concentration of 10 of these circulating miRNAs changed significantly and differently during the 3-year follow up in children who decreased or increased their normalized weight. Thus Prats-Puig et al. [64] concluded that this is the first study which provides evidence that circulating miRNAs are deranged in prepubertal children. Thus the very early detection of an abnormal circulating miRNA profiles maybe a promising strategy to identify obese children who may suffer from metabolic abnormalities [64].

\section{Obesity in adulthood: Effects of miR in WAT inflammation and IR}

Role of miRNA 125 a: While one miR can target several miRNAs, one transcript can be targeted by several miRNAs.Such interactions regulate various aspects of metabolism through pancreatic development, insulin biosynthesis, secretion and signaling, adipocyte differentiation and glucose uptake $[65,66]$. Dawara et al. studying the role of miRNA 125a in pathogenesis of insulin resistance (IR) in both men and mice studied BALB/C and C57BL/65 mice in response to high fat diet. miRNA 125a expression was downregulated in vitro in IR 3TL1 adipocytes and exvivo in adipose tissue of obese patients.In vitro modulation of miRNA 125a expression in 3T-L1 adipocytes did not affect glucose uptake.Gene set enrichment analysis (GSEA) identified significantly altered expression pattern of predicted miRNA125a gene targets in transcriptomic datasets of adipose tissue from HFDfed mice and obese patients. Among genes that contributed to global enrichment of altered expression of miRNA125a targets, thyrotroph embryonic factor (Tef), Mannan-binding lectin serine peptidase 1, Reticulon 2, and Ubiquitin-conjugating enzyme E2L3 were significantly differentially expressed in adipose tissue in these groups. They showed that Tef expression is reduced in adipose tissue of obese patient's foillowing gastric bypass surgery. Hence they concluded that miRNA 125 a expression in adipose tissue adapts to IR and may play a role in the development of obesity, both in mice and obese subjects coupled through uncoupled regulation of the expression of miRNA125a and its targets [67].

miR in adult obese vslean reflecting WAT inflammation: Ortega et al. performed miRNA array on human subcut Ortega et al. [68] performed miRNA array on human subcutaneous AT.50 of the 799 miRNA tested (6.2\%) significantly differed between obese $(n=9)$ and lean $(n=6)$ subjects (17). Among these 50 miRNAs 17 were highly correlated with BMI and metabolic parameters (fasting glucose, and or triglycerides). These data were concordant with those obtained in overweight and obese patients by Kloting et al. [69]. They showed significant correlations between the expression of selected mi RNA and both AT morphology, key metabolic parameters including visceral fat area, $\mathrm{HbAlc}$, fasting plasma glucose and circulating Lep, Adiponectin (Apn) and IL-6 [18]. Another 2 miRNAs, miRNA 17-5p, and miR132 were significantly decreased in the omental fat and circulation of obese subjects [69].

Effects of proinflammatory cytokines: Adipocytes are continuously stimulated by proinflammatory cytokines such As TNF-a which cause adipocyte dysfunction by facilitating the inflammatory response .Although $\mathrm{miR} 130$ was reported to be an important regulator of adipogenesis by targeting PPAR- $\gamma$ mRNA, little is known about the mechanisms regulating miR 130 expression during the proinflammatory response. Kim et al. examined miR 130 levels in white adipose tissue (WAT) from high fat fed diet (HFD) mice and TNF- $\alpha$ stimulated adipocyte [70]. Primary microtranscripts of miR130were increased after TNF- $\alpha$ stimulation indicating that induction of miR 130 during the post inflammatory response is regulated by a transcriptional event. A chromatin immunoprecipitation assay showed that p65 binding to the promoter regions of the miR 130 was enhanced after TNF- $\alpha$ treatment. These findings suggest that induction of miR130 by TNF- $\alpha$ is responsible for adipocyte dysfunction [70]. Obesity is associated with low grade inflammation of WAT which can subsequently lead to IR, impaired glucose tolerance and even DM. miRNAs have been implicated as negative regulators, controlling diverse biological processes at the level of post transcriptional repression. miR $146 \mathrm{~b}$ is an intergenic miRNA, that can regulate the inflammatory process by attenuating cytokine signaling via the nuclear KB pathway. Shi et al

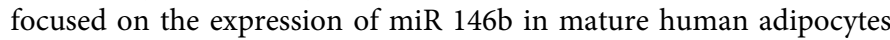
and their response to proinflammatory cytokines. They found miRNA $146 \mathrm{~b}$ was highly expressed in the mature adipocytes. The mature human adipocytes responded to proinflammatory cytokines (TNFa and IL-6) by highly increasing the expression of miR146b. They cloned and identified a potential promoter of the transcriptional regulator of miR146b. Interestingly they found a fragment about 950bp length upstream sequences of miR146 b had apparent transcriptional activity. In addition the increase in miR $146 \mathrm{~b}$ promoter activity by TNF- $\alpha$ and IL- 6 was also effectively elevated. Thus these results indicated a novel role for miR 146b in AT inflammation and miR146b may be an important mediator in the process of obesity complications via its own transcription mechanisms [71].

Role of miR 26b: Subsequently the same group investigated the effects of energy source material and hormones associated with obesity 
Citation: Kaur KK, Allahbadia GN, Singh M (2015) An Update on Microrna's and Metabolic Regulation with Future Therapeutic PotentialsRegarding Diagnosis and Treatment of Obesity, Metabolic Syndrome and Other Related Disorders. J Health Med Informat 6: 184. doi: $10.4172 / 2157-7420.1000184$

on miR26b, which is an obesity related intronic miRNA located in the intron of the carboxy terminal domain, RNA polymerase II, polypeptide A, smallphosphatase 1gene. miR26 is abundantly expressed in mice and mature human adipoytes. They demonstrated that free fatty acids (FFA) glucose, glucocorticoids and growth hormone $(\mathrm{GH})$ downregulate the expression of miR26 $b$ in human adipocytes. These results indicate that the expression of miR26b is affected by a variety of factors that are correlated with obesity and insulin sensitivity. Therefore mIR26b may be an important mediator of the development of obesity associated IR [72].

Effects of bariatric surgery: Obesity is considered a multifactorial disease, with epigenetic alterations and modifications described in expression of some miRNAs and proteins. Adipose tissue (AT) is formed by different cell types and has an endocrine function, since it secretes substances such as leptin (LEP), insulin like growth factor 1(ILF1), interleukin-10(IL-10) [73-77]. Collares et al in an attempt to study the correlation of obese patients studied the gene expression of LEP, LEP receptor (LEPR), IGF1 and IL-10 and of miR 27a, miR27b, miR143, miR145. RNA was extracted from biopsies of subcutaneous tissue and visceral fat of 15 obese subjects submitted to bariatric surgery and of 15 non obese subjects submitted to cholecystectomy for cDNA synthesis and for RTPCR.The miRNA were chosen using the Target Scan software. An increased expression of LEP and IGF1 was identified in the subcutaneous fat of the obese group as compared to control, while the expression of IGF1 was higher in the control groupthan in obese one. miRNA 27a had a higher expression in the omentum of the obese patients.There was a positive correlation in the expression of miRNA145 and LEPR in the omentum of the group [78].

Interrelation of hypoxia and cytokines in FA storage: Recent findings in adipose tissue (AT) have uncovered negative interactions among obesity, lipogenesis and fatty acid (FA) storage, perhaps in response to the increased production of proinflammatory cytokinesand transcription factors. Emerging evidence highlights that local hypoxia, generation of reactive oxygen and nitrogen species, increases immune cell infiltration and activation,senescence, inflammation, energy consumption and decreased lipogenisis in AT are interrelated and may lead to impaired cytokine and hormonal secretion by adipocytes, and ectopic fat deposition in obesity that strengthens the increased risk of suffering metabolic disorders in obese subjects.That "inflammed" and "dysfunctional" AT are synonymous when referring to obesity, is defended by Ortega et al. and they tried to explain how it may happen in severe obese subjects having a large and longtime fat excess., when fat deposits have reached a point when excessive fat storage,cell density, and diminished oxygen availability promote decreased lipo/adipogenesis and increased lipolysis and FA release. This response maybe an important inflammatory component that promotes angiogenesis and IR, but also by leptin and increase of T3 in hyperplastic AT $[78,79]$.

Role of hypoxia: Hypoxia induces a complex and still incompletely understood adaptations that influence cell survival and function. Many of these adaptations are directly controlled by a master transcription factor, hypoxia inducible factor alpha (HIF- $\alpha$ ) Role of hypoxia and miR 210: In response to hypoxia, HIF- $\alpha$ levels increase and directly induce the transcription of $>100$ genes, influencing function ranging from metabolism, survival, proliferation, migration angiogenesis among others. Recently, it has been demonstrated that a specific set of miRNA molecules are upregulaed in hypoxia, which are denoted as "hypoxamirs". Specially the HIF-responsive hypoxamir miRNA 210 is a unique miRNA that is evolutionsally conserved and ubiquitously expressed in hypoxic cell and tissue types. A number of direct targets of miR210 have been identified in silico, transcriptional and biochemical methods, a subset of which has been extensively validated. As a result
miR 210 has been mechanistically linked to the control of wide range of cellular responses known to influence normal developmental physiology as well as a number of hypoxia dependent disease states including tissue ischaemia, inflammation and tumorigenesis. Thus reflecting the pleiotropic acions of HIF- $\alpha$, miR210 appears to function as a "master microRNA" relevant to the control of diverse functions of hypoxic state [80].

Role of mIR 322 in ER stress: The disruption of the energy or nutrient balance triggers endoplasmic reticulum (ER) stress, aprocess that mobilizes various strategies collectively called the unfolded protein response (UPR) which reestablishes homeostasis of the cell [81]. Activation of the UPR stress senses IRE-1a (Inositol requiring enzyme $1 \alpha$ ) stimulates the endoribonuclease activity leading to the generation of mRNA encoding the transcription factor XBP-1(X-box binding protein-1) which requires the transcription of genes encoding factors involved in controlling the quality and folding of proteins Groennendy et al. [81] found the activity of IRE $1 \alpha$ was regulated by the ER oxidoreductase PD1A6 (Protein disulfide isomerase A6) and the miR322 in response to disruption of $\mathrm{ER} \mathrm{Ca}^{2+}$ homeostasis. PD1A6 interacted with IRE1- $\alpha$ and enhanced IRE- $1 \alpha$ and XBP1mRNA splicing but PD1A6 did not substantially effect the activity of other pathways that mediate responses to ER stress. ER $\mathrm{Ca}^{2+}$ depletion and activation of storeoperated $\mathrm{Ca}^{2+}$ entry reduced the abundance of the miR322 which increases PD1A6 mRNA stability and consequently IRE- $1 \alpha$ to activity during the ER stress. Responses in vivo experiments with mice and worms showed that the induction of ER stress correlated with decreased miR322 abundance, increased PD1A6 mRNA abundance or both. Together these findings demonstrate that ER $\mathrm{Ca}^{2+}$ PD1A6, IRE$1 \alpha$, and miR322 function in a dynamic feedback loop, modulating the UPR under conditions of disrupted $\mathrm{ER} \mathrm{Ca}^{2+}$ homeostasis [82].

ER stress and the UPR lead to obesity induced inflammation and metabolic abnormalities by several distinct mediators including the activation of JNK-AP-1(Jun $\mathrm{N}$ terminal kinase-activator protein 1 ) and IKK (IkB kinase) NFKB pathway, the induction of the acute phase response and the production of reactive oxygen species (ROS) $[83,84]$

MiR's regulating WAT inflammation: Expression of miR 221 and miR 222 has been positively correlated to TNF- $\alpha$ and negatively correlated to adiponectin $(\mathrm{ApN})$ expression in WAT of mice [85]. miR 132, which wasdownregulated in human obese omental fat [86] has been reported to activate NF- $\kappa B$ and the transcription of IL- 8 and MCP 1 in primary human preadipocytes and in vitro differentiated adipocytes. Zhuang et al. [87] demonstrated that miR 223 played a crucial role in modulating macrophage polarization in a pattern that protects mice from diet induced AT inflammation and systemic IR. Consequently miR 223 suppressed the infiltration of proinflammatory M1 classicaly activated macrophages by targeting Pknox1 in vitro, while miR 223 deficient mice fed a HFD exhibited increased AT inflammation characterized by enhanced proinflammatory activation of macrophages [88]. In macrophages functional polarization is associated with the upregulation of distinct set of miR's [89,90]. TLR4 mediated activation of NF-KB induces a negative feedback loop by upregulating miR's such as $\mathrm{miR} 21$, miR $147, \mathrm{miR} 210, \mathrm{miR} 34 \mathrm{a}$ and miR 146 which dampen TLR induced signaling and cytokine expression [90-92]. In contrast mIR 155 shows both anti and proinflammatory effects by regulating TAB2 $\alpha$ and SOCS 1 respectively.

Ge et al. reported several miR's which were regulated by adiponectin in WAT in vivo. The miR $883 \mathrm{~b}-5 \mathrm{p}$, which was upregulated by ApN and down regulated in obesity, repressed the LPS binding protein (LBP) and TLR4 signaling, acting therefore as a major mediator 
Citation: Kaur KK, Allahbadia GN, Singh M (2015) An Update on Microrna's and Metabolic Regulation with Future Therapeutic PotentialsRegarding Diagnosis and Treatment of Obesity, Metabolic Syndrome and Other Related Disorders. J Health Med Informat 6: 184. doi: $10.4172 / 2157-7420.1000184$

Page 5 of 16

of the anti-inflammatory action of ApN. miR 883b-silencing in the denovo AT formed from in vivo differentiation of preadipocytes also induced LBP production and tissue inflammation [92]. Further Ishida et al. found levels of premiR 378 to modulate ApN expression via the 3'UTR sequence binding site.They found levels of ApN mRNA andprotein were decreased in 3T3-L1 cells overexpressing the mimc of miR378 both in silico study and confirmed by luciferase assay [93]. To understand how increased chemokine motif ligand 2 (CCL2) secretion may initiate adipocyte inflammation Arner et al. studied miRNA's which are dysregulated in obesity.Of these they overexpressed 9 indiviual miRNA's which have been defined dysregulated in AT in human obesity in human adipocyte differentiated in vitro. Of the 10 they found 9 significantly reduced the CCL2 which is an initiator of AT inflammation by attracting the migration of inflammatory cells into the tissue. Among these 10 affected adipocyte CCL2 secretion in vitro and for 2 miR's miR 126 and 193 b regulatory circuits were defined. Among these miR's only miR 126 was predicted by in silico analysis and confirmed by luciferase transcription assays in 3 T3-L1 cells to bind directly to 3'UTR of CCL2 whereas miR 193 b affected indirectly CCL2 production through downregulating transcription factors (TF's) of CCL2 (RELB, STAT6, and ETSI). The levels of 2 miR's in subcutaneous WAT were significantly associated with CCL2 secretion of integrin $a-X$ mRNA levels (a gene specific for proinflammatory (M1) macrophage marker ). Thus they concluded that miR's regulate AT inflammation through their effects on CCL2 release from human adipocytes and macrophages [94]. Thus miR's may mediate AT inflammation by regulating either the activation of macrophages or the production of adipokines.

\section{Role of Circulating MicroRNAs in Obesity}

\section{Cicrculating miR's as biomarkers}

Based on Genome wide studies having yielded important insights into the pathogenesis of obesity and that circulating miRNAs have been stable biomarkers of systemic diseases and potential therapeutic targets, Ortega et al. assessed genome wide circulating miRNAs profile cross sectioning 22 men and after surgery induced weight loss in 6 morbidly obese patients. The most relevant miRNAs were cross sectionally validated in 80 men and longitudinally in 22 patients (after surgery induced weight loss). They evaluated the effects of diet induced weight loss in 9 obese patients. 36 miRNAs were associated with anthropometric variables on the initial sample. In the validatation study morbidly obese patients showed a marked increase of miR $140-5 p, m i R$ $142-3 p$, and miR 222 and decreased levels of miR 532-5p, miR125b, miR130b, miR221, miR15a, miR423-5p, and miR520c-3p. Intrestingly in silico targets leukemia inhibiting factor (LIF), transforming growth factor receptor (TGFR) of miR140-5p, miR142-3p, miR $15 a$, miR520c-3p circulated in association with their corresponding miRNAs. Moreover a discriminant function of three miRNAs, miR15a, miR520c-3p, and miR423-5p was specific for morbid obesity with an accuracy of $93.5 \%$. Surgery induced (but not diet induced) weight loss led to a marked decrease of miR140-5p, miR122, miR193-a-5p and miR 16-1 and upregulation of miR221 and miR199a-3p. Thus they concluded that circulating miRNAs are deregulated in severe obesity. Weight loss induces changes in the profile of and the study of in silico targets supports this observation and suggests a potential mechanistic relevance [95].

Since miRNAs changed in relation to different modes of treatment ,this finding suggests that miRNA are related to the process by which the body weight is lost rather than an effect arising for example from shrinking adipose organs [96]. Further although Ortega et al. identified changing serum miRNA profiles they do not speculate on how these miRNAs are transported, whether they are protein or HDL bound or contained within exosomes maybe of mechanistic relevance. Extracellular vesicles are well described to mediate cell-cell communicationby fusing with remote cells and transferring bioactive contents such as DNA, RNA and cytokines. The findings of miRNA within circulating vesicles raises the possibility that miRNA may also be transferred to recipient cells $[95,97]$.

\section{Micro RNAs as biomarkers for DM in obesity}

Biomarkers in medical care are bench mark in the body preferably in blood circulation that can be reliably evaluated to indicate the presence of physiological and metabolic disturbances [98]. Several components associated with the pathophysiology of type2 diabetes mellitus (T2DM) have been uncovered in the last decades, being the result of alteration in insulin secretion coupled with changes in insulin action in insulin sensitive tissue (i.e. muscle, liver andAT) and modulated by complex multifactorial webs of relationships [99]. In this new scenario, virtually all tissues and systems are active players modulating both insulin action and response. The existence of these complex systems aimed at regulating energy balance, in close association with the immune system and chronic inflammation, calls for a broader view of the paradigm [99]. In this context it has been postulated that circulating miRNAs could act as a new model of communication between insulin sensitive tissues from obese or T2DM patients suggesting a potential role for these small RNA molecules in the complications associated with the metabolic complications $[100,101]$. During last 5years it has been demonstrated that miRNAs are not only intracellular molecules, since they are also detectable outside the cell $\mathrm{s}$ in body fluids (e.g., in serum, plasma, saliva, urine and milk) [102]. They are protected from degradation by RNAses because they are contained in small membranous vesicles (e.g., exosomes, exosome like vesicles, microparticles and apoptotic bodies [103], packaged within HDL [104] and linked to RNA binding proteins (e.g., argonaute 2 and nucleoplasmin 1 [105]. It has been suggested that extracellular miRNAs have specific physiological functions depending on their cellular origin and regulating immune function, cell migration, differentiation and other aspects of cell-cell communication $[101,105]$.

Hence the concept that extracellular miRNAs contained in body fluids could be used as biomarkers for the detection and classification of disease has been proposed [106]. Their presence in plasma and the possibility of detecting and small interindividual variations make circulating miRNAs excellent potential biomarkers for complex systemic diseases eg T2DM $[102,107,108]$. Thereby body fluids miRNAs could provide an integrated view of the metabolic profile of T2DM patients [109]. Hence by means of both cross sectional and longitudinal analysis in men which included placebo controlled with metformin, acute insulin-hyperinsulinemic-euglycemic clamp) and insulin infusion and intralipid/heparin known to induce IR [110], this study by Ortega et al. aimed to identify circulating miR 's associated with T2DM and their responses to insulin sensitivity.In an attempt to identify the profile of circulating miRNA' $s$ in T2DM and its response to changes in insulin sensitivity, Ortega et al. assessed in 12 men, 6 with normal glucose tolerance(NGT) and 6T2DM patients [111]. The Association of 10 circulating miRNAs with T2DM was cross validated in an extended sample of $45 \mathrm{NGT}$ vs $48 \mathrm{~T} 2 \mathrm{DM}$ subjects (65 nonobese and 25 obese men) and longitudinally in 35T2DM patients who were recruited in a randomized double blind and placebo controlled 3 month trial of metformin treatment. Circulating miRNAs were also measured in 7 healthy volunteers before and after a $6 \mathrm{~h}$ hyperinsulinemic-euglycemic clamp and insulin plus intralipid/heparin infusion. Amarked increase 
Citation: Kaur KK, Allahbadia GN, Singh M (2015) An Update on Microrna's and Metabolic Regulation with Future Therapeutic PotentialsRegarding Diagnosis and Treatment of Obesity, Metabolic Syndrome and Other Related Disorders. J Health Med Informat 6: 184. doi: 10.4172/2157-7420.1000184

of miR140-5p, miR142-3p and miR222 was disclosed by crosssectional studies along with decreased miR 423-5p, miR 125-b, miR192, miR 195, miR130b, miR 532-5p, and miR126 in T2DM patients. Multiple linear regression analysis revealed that miR140-5p and miR423-5p, contributed independently to explain $49.5 \%$ of fasting glucose variance after controlling for confounders. A discriminant function of four miRNA (miR140-5p, miR423-5p, miR195 and miR126) was specific for T2DM. With an accuracy of $89.2 \%$ Metformin \{but not placebo led to significant changes in circulating miR $192(49.5 \%)$, miR140-5p $(-15.8 \%)$, and miR222 $(-47.2 \%)$ in parallel to decrease fasting glucose and $\mathrm{HbA1C}$. Furthermore while insulin infusion during clamp decreased $\mathrm{miR} 222(-62 \%)$, the intralipid/heparin infusion mixture increased circulating miR222 (163\%) and miR140-5p (67.5\%). Thus concluding the close association between variations in circulating miRNAs and T2DM and their potential relevance in insulin sensitivity [112].

Leroith commented that the strength of study of Ortega et al. lies in identifying miRNAs, that are associated with obesity, IR, and T2DM as well as aresponse to metformin therapy.But weakness relates to the relatively small sample size with some aspects of their study and absence of the effects of other medications [111,113].

Further questions posed are 1) do circulating miRNAs represent biological markers for various metabolic disorders [114] 2) Do miRNAs truly function as intercellular regulators. 3) How are miRNA levels controlled at the cell of origin? 4) How do lifestyle and other pharmaceutical agents affect miRNA expression and levels in the circulation thermogenic adipocytes?

\section{Role of chromium deficiency and miR375/30d}

Chromium deficiency leads to impaired glucose tolerance, due to IR and hyperglycemia [115]. Trivalent chromium is a complex known as glucose tolerance factor, such as chromium picolinate, is considered the biologically active form. To study the antidiabeic effect of TIAN MAI (TM) Xiaoke tablet commonly used in China to treat DM which contains chromium picolinate $(1.6 \mathrm{mg} / \mathrm{tab}=200 \mathrm{mg}$ snake gourd root, dwarf aily urf tuber and Chinese magnolia vine fruit in ratio of 1.6:62.5:62.5:25) and is found to be effective in reducing HBA1c Zhang et al. studied diabetic mice to study the mechanism of action using low dose TM L and high dose of TM groups before and after oral glucose administration and studied fasting insulin HOMA-IR. Eight weeks regimen significantly reduced in TM treated before and after oral glucose administration and HOMAIR insulin were suppressed in TM treated groups. miR448, let 7b, miR540, miR296, miR880, miR200a, miR-500, miR10b, miR336, miR30d, miR208, miR501, miR188 were upregulated, while miR10 b, miR134 and miR652 were downregulated. Through target gene analysis and real time PCR verification they found these miRNAs especially, miRNA375 and miRNA30d can simulate insulin secretion in islets. Hence they concluded that TM improves blood glucose in diabetic rats by involving expression of miRNA375 and miRNA30d to activate insulin synthesis in islets and possibly that is how it had been working in Chinese patients treated with TM $[115,116]$.

\section{Regulation of Cholesterol and Fatty Acid Metabolism and miRNAs}

Introduction: Lipid homeostasis is regulated by a family of membrane bound transcription factors called sterolregulatory element binding proteins (SBERP's [117-119] which directly activate the expression of $>30$ genes involved in synthesis and uptake of cholesterol,
FA's, triglycerides and phospholipids as well as the NADPH cofactor required to synthesize these molecules. Of The SREBP isoforms SREBP1 is selectively involved in activating genes involved in FA metabolism and denovo lipogenesis, whereas SREBP2 is more selective for genes involved directly in cholesterol homeostasis [117-119]. Aberrant expression of SREBP's in mice leads to metabolic syndrome (MS) with physiological effects similar to specific disorders of lipid metabolism in humans [117-119]. Besides SREBP's the liver X receptor (LXR's) are also important transcriptional regulators of cholesterol metabolism $[120,121]$. LXR $\alpha(\mathrm{NR} 1 \mathrm{H} 3)$ and LXR $\beta$ (NR1H2) nuclear receptors form heterodimers with retinoid $\mathrm{X}$ receptors and are activated by a variety of sterol including oxysterol intermediates that form during cholesterol biosynthesis [121]. LXR's activate the transcription of genes involved in cellular cholesterol efflux, including Abcaland Abcg1 [122]. LXR's also impact SREBP 1trancription, thereby mediating crosstalk between these pathways to increase FA synthesis [122]. Mice with targeted deletion in the LXRA gene were noted to be deficient in expression of SREBP1c, fatty acid synthase (FAS), SCD1 (steroyl CoA desaturase 1) and ACC (Acyl coA Carboxylase) [122,123].

\section{Micro RNAs and lipid metabolism}

Of the several miRNAs highlighted till date miR122, miR370, miR378/378*, miR335, miR125a-5p and miR33 are the important regulators of lipid metabolism.

Role of miR122: miR122 was initially identified as a highly abundant miRNA in the liver, accounting for $70 \%$ of initial miRNA expression [124]. MiR122 has been associated with the regulation of liver metabolism as well as hepatitis C infection (HCV), and has been shown to be downregulated in hepatocellular carcinoma (HCC) [125-128]. Astudy employing cholesterol conjugated antisense oligonuclotides (termed antagomiRs showed that injection of antagomiRs that target miR122 into mice resulted in altered hepatic expression of a number of genes including some involved in cholesterol biosynthesis such as 3hydroxy -3methyl glutaryl-coenzyme A Reductase (Hmgcr), 3-hydroxy-3-methylgltaryl-CoA-synthase 1 (Hmgcs1) and 7-dehydrocholesterolreductase (Dhcr7) [126]. The use of antisense miR122 down regulated several genes implicated in liver metabolism and produced an increase in expression of hundreds of genes that are normally repressed in hepatocytes suggesting that miR122 functions to maintain the liver phenotype [125,126]. In addition several genes involved in FA synthesis and oxidation were altered in mice treated with antimiR122 including FAS, ACC1 and ACC2 [125,126]. Silencing of miR122 in high fat fed mice induced hepatic steatosis which was linked to a reduction in cholesterol synthesis and stimulation of FA oxidation [126]. In contrast, two independent studies have recently shown that mice lacking miR 122 in the liver or in the germline develop steatohepatitis by increasing the expression of genes involved in TG synthesis, including 1-acyl glycerol-3-phosphate acyl transferase alpha (Agpat1), Agpat3, Agpat9, Monoacyl glycerol-O-acyl transferas (Mogat1), phosphatidic acid phosphatase-2a (Ppap2a and PPap2c) $[129,130]$. Further studies are needed in order to explain the differences observedbetween miR silencing using ASO and miR knockdown.

Role of miR370: MiR370 targets carnitine palmitoyl transferase (Cpt1a), a mitochondrial enzyme that mediates the transport of long chain FAs across the membrane by binding them to carnitine, thereby reducing FFA oxidation [131]. miR 370 transfection of human hepatic cell lines Hep G2 upregulates the expression of miR122 leading to increased expression of lipogenic genes including SREBP1c and DGAT2 which suggests that miR370 provides an additional point of regulation of this pathway [131]. 
Citation: Kaur KK, Allahbadia GN, Singh M (2015) An Update on Microrna's and Metabolic Regulation with Future Therapeutic PotentialsRegarding Diagnosis and Treatment of Obesity, Metabolic Syndrome and Other Related Disorders. J Health Med Informat 6: 184. doi: 10.4172/2157-7420.1000184

Page 7 of 16

Role of miR378/378*: MiR378/378* is an intronic miRNAlocated within the PPAR- $\gamma$ coactivator 1 alpha $(\mathrm{PGC1}-\alpha)$ genomic sequence. Overexpression of $\mathrm{miR} 378 / 378^{*}$ during adipogenesis increases triacylglycerol accumulation [132]. Transfection with miR378/378* of adipocytic ST2 cells leads to increased expression of FA metabolism genes including FAS, fatty acid binding protein 4 (FABP4), and sterolcoenzyme-A desaturase 1 (SCD1) [132].

Role of MiR33 as a key regulator of lipid metabolism: The group of Marquart TJ et al., Najafi-Shoushtari et al. and others identified a highly conserved miRNA family, miRNA 33, within the intronic sequences of the Srebp genes [132-135]. Two miR33 genes are present in human miR33b, which is encoded within intron 17 of Srebp 1 geneon chromosome 17 and miR33a which is expressed in intron 16 of the Srebp-2 gene on chromosome 22. In mice however, there is only one miR33 gene which is the ortholog of human miR33a and is located within intron 15 of the mouse Srebp-2gene. miR33a and miR33b are cotranscribed with its host genes, like many intronic miRNAs and they target genes involved in regulating cholesterol homeostasis (Abca1,Abcg and Npc1) [135-138] and fatty acid metabolism (Ampk, Cpt1a, Crot, Hadhb and Sirt6) [136,137]. During miR biogenesis premiR33 (as well as other premiR's) is cleaved with dicer which leads to the creation of a miR33 duplex composed of mature miR33 and passage miR33 (miR33") strands . As Shown by Goedecke et al. in 2013, miR33 is one of the examples where both strands are loaded into RISC and consecutively execute their tightly related function, thereby affecting cholesterol metabolism [133-139], fatty acid metabolism (136, $138 \mathrm{~g})$ glucose metabolism/insulin signaling $[136,138,140]$. Within the cholesterol metabolism, both miR33 and miR33" target ABCA1 and Niemann-Pick disease C1(NPC1), that is, molecules importantfor loading cholesterol into HDL particles and for cholesterol transport from the lysosomal compartment within the cell respectively [133138]. miR 33 itself was further shown to target ABCG1 in mice, which has a similar function to ABCA1, that is enabling HDL formation and reverse cholesterol transport (e.g., cholesterol transport from atherosclerotic plaque macrophages back to the liver); however this target was not confirmed in humans [133,135]. Interestingly both ABCA1 and ABCG1 are under the transcriptional control of LXR [133] and miR33 thus provides the connecting link between SREBP induced cholesterol synthesis and retention and LXR mediated cholesterol efflux and reverse cholesterol transport [141]. In addition to above , miR 33 targets ABCB11 and ATP8B1, both of which are important molecules in cholesterol efflux into biliary ducts; this targeting thus supports cholesterolretention caused by the upregulation of SREBP and miR33 in hepatocytes [139] (Figure 2). This upregulation maybe induced by extracellular signals including low c irculating cholesterol levels or statin therapy [139]. Confirmed targets for both miR33 and miR33* in the fatty acid metabolism include carnitine palmitoyltransferase $1 \mathrm{~A}$ (cpt1a) and carnitine O-octaniltransferase (CROT) [136-138]. Furthermore, miR 33 also target hydroxyl acyl-Co-A-dehydrogenase (HADBH) [136,137], sirtuin 6(SIRT6), and AMPKa [136], while miR33* targets sterol receptor coactivator1 (SRC1), SRC3, Nuclear transcription factor Y (NFYC), and receptor interacting protein 140(RIP140). By regulating all of these molecules post-transcriptionally, both miR33 and miR33 reduce fatty acid oxidationwhen upregulated and vice versa, that is stimulating the process when downregulated [136,138]. MiR 33 also influences insulin signalling by targeting insulin receptor substrate 2 (IRS2), thereby affecting both lipid and glucose metabolism [136], with the glucose metabolism also being affected by glucose-6-phosphatase (G6PC) and phosphoenolpyruvatecarboxykinase targeting [140]. Thus therapeutic downregulation of their signalling may be beneficial in patients suffering from atherosclerosis, as it would result in an increase of HDL levels and a decrease in fatty acids and glucose levels.

These findings suggest that Srebp genomic loci, which encode transcription factors and $\mathrm{miR} 33 \mathrm{a} / \mathrm{b}$ may cooperate to regulate lipid metabolism [141,142]. Inhibition of miR33 using different strategies increases plasma high density lipoproteins (HDL) in mouse and promotes the expression of atherosclerosis in mice [133-135,143,144].

Altogether these observations suggest that intronic miRNAs work in conjunction with host genes to regulate similar cellular processes. Since SREBP's regulate cellular proliferation and cell cycle progression, Cirera-Salinas et al. tested the role of miR33 in regulating these cellular functions. They identified putative binding sites for miR33 in the 3'UTR of cycles dependent kinases (Cdk6,Cdk8 and Cdk19), Ccnd1, and $\mathrm{d} 2$, p53, Pten, Myc and mitogen activated protein kinase inhibitor (Map3k1, Map3k7, Map3k, Mapk6, Mapk10, Mapk14). They showed that overexpression of miR33 inhibits CDK6, and cyclin D1 expression, reduces cell proliferation in different human cell lines and leads to cell cycle arrest in G1 phase. Conversely endogenous inhibition of miR33 expression using 2'fluoromethoxy ethyl-modified (2T/MOE-modified) phosphorothioate backbone antisense oligonucleotides improves liver regeneration after partial hepatectomy in mice. Altogether concluding that SREBP-Mir33 locus may cooperate to regulate cell proliferation and cell cycle progression and may also is relevant to human liver regeneration $[144,145]$.

\section{Role of miR 143/145}

The miR143/145 cluster regulates vascular smoothmuscle cell (VSMC) specific gene expression, thus controlling differentiation, plasticity and contractile function, and promoting the VSMC phenotypic switch from a contractile/non proliferative to a migratory proliferative state [146-148]. More recently increased miR145 expressions were observed in human carotid atherosclerotic plaques from symptomatic patients [149]. Sala et al. showed that miR143/145 deficiency attenuates the progression of atherosclerosis in Lslc mice. This event could be the consequence of multiple mechanisms including changes in VSMC function and increased vascular and hepatic ABCA1 expression. miR143 has been shown to regulate adipocyte differentiation as well as a regulator of hepatic insulin signaling $[150,151]$. The expression of miR143/145 cluster is upregulated in the liver of genetic and dietary models of obesity [151]. Specifically, over expression of miR143, but not miR145, impairs insulin stimulated Akt activationand glucose homeostasis. Conversely mice deficient for the miR143/145 cluster are protected for the development of obesity associated IR [151]. Altogether these observations suggest that the effect of miR145 and miR143 in controlling lipid and glucose metabolism, might be mediated by the direct regulation of ABCA1 by miR145 and the regulatory role of miR143 on hepatic insulin signaling and adipocyte differentiation. Thus Sala et al. concluded that their results, that miR 145 inhibits ABCA1 coupled to the identification of increased miR145 levels to human carotid plaques from symptomatic patients [150], supports the relevance of evaluating anti miR145 strategies in the context of novel approaches under investigation for dyslipidemia $[152,153]$ and cardiovascular related diseases ,including atherosclerosis [154]. Based on these Muthiah et al designed a method to coat the stent surface with miR145 to suppress the overgrowth of smooth muscle cell (SMC) and used polysorbitol osmotically active transporter (PSOAT) for effective miR145 delivery and found a drastic reduction in SMC proliferation after PSOAT/miR145 nanoparticle (PEM) treatment and $\mathrm{miR} 145$ target proteins were downregulatedupon miR145 replacement. HencePEM is useful for patients with restenosis where 


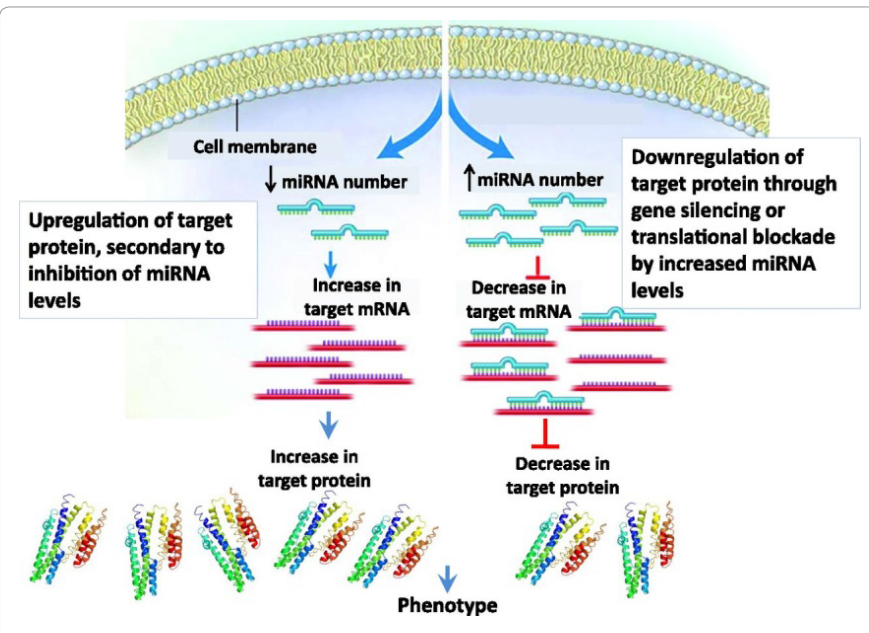

Figure 1: Mechanism for miRNA regulation of target miRNA levels. Stress signals (such as homodynamic overload activate signal transduction pathways that lead to either the up regulation or downregulation of specific miRNAs. Stress signals that increase the expression levels of miRNAs can result in the down regulation of several target miRNAs through gene silencing or, more commonly a translational blockade of the target miRNA. Alternatively a stress-induced decrease in the expression levels of inhibitory miRNAs can lead to upregulation of previously suppressed target genes. Ultimately it is the miRNA-induced pattern of change in gene expression that contributes to the resultant disease phenotype [7].

SMC's growover a stent surface and block blood flow through the stent $[154,155]$.

\section{Role of miR 27b}

MiR 33 which is encoded within an intron of SREBP2 is cotranscribed with SREBP2 and regulates the expression of ATPbinding cassette transfer proteins (ABCA1), is a critical player of reverse cholesterol transport and in Lp biogenesis [133-135]. miR 33 has also been shown to regulate fatty acid oxidation in hepatic cell lines [136]. But despite knowing that $\mathrm{miR}$ are post transcriptional regulators of gene expression and important mediators of lipid homeostasis, the extent of their control of lipid metabolism had not been systematically investigated. Hence Vickers et al. provided in silico, in vitro and in vivo evidence that $\mathrm{miR} 27 \mathrm{~b}$ is a strong candidate regulatory hubin lipid metabolism. Based on Monte Carlo simulations, miR27 b was predicted to target significantly more lipid associated genes than expected by chance and more than any other other hepatic miRNAs. Of the other miRNAs predicted to be regulatory hubs in lipid metabolism miR365 and miR125 have previously been shown to play roles in either adipocyte differentiation or in cellular lipid uptake $[156,157]$ respectively. Thus high throughput small miRNA sequencing and real time quantitative PCR analysis revealed that miR $27 \mathrm{~b}$ is 3.2 fold upregulated in the livers of mice on high fat diet. Further they showed in a human hepatic cell line (Huh 7) that miR 27b regulates the expression (mRNA and protein) of several key lipid -metabolism genes including angiopontin like 3 (Angplt3) and Glycerol 3- phosphate acyl transferase (Gpam). Finally they demonstrated that hepatic miR27b and its target genes are inversely altered in a mouse model of dyslipidemia and atherosclerosis. They suggested further detailed in vivo experimentation to determine the extent of which miR27b targeting of ANGPTL3 and GPAM is required for controlling lipid levels and modulating $\mathrm{miR} 27 \mathrm{~b}$ could prove an effective strategy for lipid related disorders [158].

\section{Role of lipoproteins}

Lipoproteins represent a highly evolutionary conserved system to transport lipids, proteins and also miRNA's in circulation. The interaction between specific protein of Lp's and their receptors in cell membrane ensures a selective interaction and exchange of Lp transported moieties. Although both LDL and HDL have been shown to transport miRNAs, they present a different miRNA signature with LDL presenting a miRNA profile closer to that of plasma exosomes than that of HDL [104]. HDL represents, so far the only class of Lp widely studied for its ability to retrieve, transport and deliver miRNAs to cells. HDL reconstituted with human apolipoprotein A1 (Apo-A1) and phosphatidyl choline (rHDL) is able to retrieve a large amount of miRNAs in vivo. Following injection of rHDL in mice (wild type or Apo-E deficient on chowor atherogenic diet) the majority of miRNAs retrieved by the Lp's were the same independently of mice genotype or the presence of atherogenic diet; however the presence of atherogenic diet was associated with relatively different amount of miRNAs loaded on HDL [104]. Lu D speculated that Apo-A1 might bridge the Lp to the cells, and zwitterionic PC, that was shown to complex small RNAs, might bind the miRNA's. miRNA export from macrophages to HDL is favoured by the expression of ABCA1 expression, but also by the inhibition of the ceramide pathways [158]. The latter was shown to promote miRNA export to exosomes [159160], therefore the possibility that miRNAs loading on HDL or exosomes could be related to the different bioavailability of cellular lipids should be investigated. The delivery of miRNA from HDL in cells is highly dependent on scavenger receptor B1 (SR-B1), SR-B1, a scavenger receptor with a mission to transport HDL lipids, which may also lead to less degradation of miRNA's. Indeed rHDL-miR223 complex when incubated with hepatocytes releases miR223 to the cells and reduced the expression on their targets into the cells [104]. Although a subsequent study by Wagners et al. confirmed results of Vickers et al. in the case of in vitro modelsof endothelial cells, SMC's and macrophages, the study indicatedthat the miR uptake is not sufficientdue to the lowamounts of miR being transferred from HDL to target cells [160]. Interestingly, Wagner et al. also also showed that naivve HDL particlesare able to cause transient downregulation of some miR's in the recipient cells, which is most likelycused by pumping of miR's into the HDL [160]. None of the miRNA's known to modulate lipid metabolism are among those prevalenton human HDL from healthy subjects or patients with familial hypercholesteremia.This raises the possibility that miRNAs carried by HDL could influence pathways other than those strictly related to lipid metabolism. For e.g., HDL is emerging as a new player in immunity [161-163] and in silico analysis predicted that the most abundant miRNAs present on human HDL might affect the signaling pathways associated with innate and adaptive immunity [104].

\section{Role of miR223}

miR223 is one of the most abundant miRNAs in monocytes and macrophages and a key regulator of inflammation [164]. miR223 null mice have a significantly increased number of circulating neutrophils and enhanced systemic inflammation following lipopolysaccharide challenge [164]. Further extending their study Remaley's group showed that HDL suppresses expression of intercellular adhesion molecule 1(ICAM 1) through the transfer of miR223 in endothelial cells. After incubation with HDL, mature miR223 levels are significantly increased in EC's and decreased on HDL. However, miR223 is not tanscribed in EC's and is not increased in cells treated with HDL, from miR223-/mice. HDL inhibits ICAM1 protein levels, but not in cells pretreated with miR223 inhibitors. ICAM1 is a direct target of HDL-transferred miR223 and this is the first example of extracellular miR regulating gene expression in cells where it is not transcribed.In this study they established that mature miR 223 is abundant in EC (HCAEC 


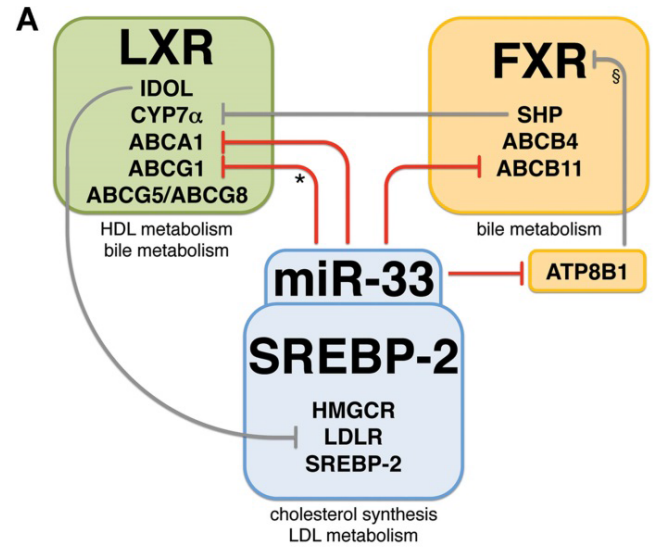

B

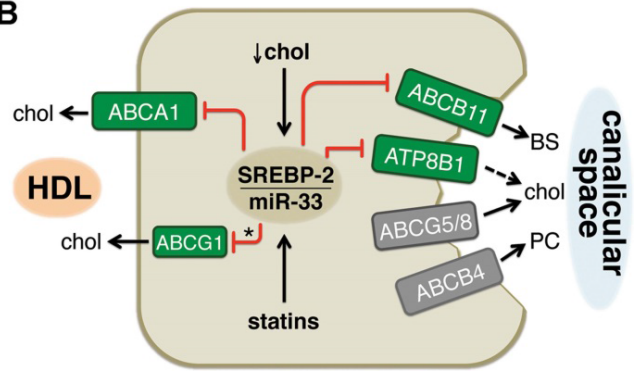

Figure 2: miR33 limits the mobilization of sterols in hepatocytes through both the sinusoidal and canalicular membrane. [139] A) miR33 mediates the crosstalk between the SREBP-2, LXR, FXR pathway by directly modulating the expression of ARP8B1, ABCB11, ABCA1and ABCG1 in mice. Decreased ATP8BP1activity in humans but not in mouse, hepatocytes, results in PKCdepedent inactivating phosphorylation of FXR. B) During episodes of low cholesterol or following treatment with statin drugs, miR33 is transcriptionally induced and reduces the expression of sterol transporters.

and HUVEC) where it is neither transcribed nor processed. This is explained by the transfer of mature miR223 from HDL to both HCAEC and HUVEC. HDL also transfers functional miR223 to HCAEC where it controls inflammatory gene expression. It is therefore likely that, in the context of atherosclerosis and other inflammatory diseases macrophages export miR to HDL, which in turn transfer miR223 to EC's as a feedback mechanism to antagonize inflammation [165]. The levels of extracellular miRNA, specifically HDL-miRNA223 levels are altered in disease states including atherosclerosis [104,166]. Further Vickers et al. identified that genetic ablation of miR223 in mice resulted in increased HDL-C levels and particle size, as well as increased hepatic and plasma total cholesterol levels. They summarized that miR 223 plays a critical role in systemic cholesterol regulation by coordinated posttranscriptional control of multiple genes in lipoprotein and cholesterol metabolism [167].

\section{Role of miR 155}

Hepatic steatosis is a globalepidemic that is thought to contribute to the pathogenesis of type 2 diabetes. Hepatic expression profiling has revealed temporal changes in miR expression in human and murine nonalcoholic fatty liver disease(NAFLD), and identified several differentially expressed miR's including miR 21,miR34, and miR122 [168]. In addition, it has been shown that miR155 expression is increased in murine models of NASH and HCC and its expression correlated with disease severity. In line with these miR155 target genes, C/EBP beta (Cebpb) and Suppessor of cytokine signaling 3 (Socs3) were decreased. miR155 is a multifunctional miRNA known to regulate numerous biological processes including haematopoiesis, inflammation, satherosclerosis and cancer [169]. Hence Miller et al. reported that the absence of miR155 in mice fed HFD was associated with a significantly inceased hepatic steatosis andV LDL/LDL cholesterol levels and alanine transaminase (ALT) levels, as well as increased hepatic expression of genes involved in glucose regulation (Pck1,Cebpa), fatty acid uptake (CD36) and lipid metabolism (Fasn, Fabp4, Lpl, Abcd2Pla2g7). Using miR target prediction algorithms and the microarray transcription profile of miR155 -/- livers they identified and validated liver $\mathrm{x}$ recetor $\alpha(\mathrm{LXR} \alpha)(\mathrm{Nrlh} 3)$ as a direct miR155 target gene that ispotentially responsible for the liver phenotype of miR155-/mice. Thus, their data directly implicates miR 155 in liver homeostasis and its deregulation as a pivotal factor in the pathogenesis of fatty liver diseases [169].

\section{Role of miR 30c}

High plasma lipids are risk factors for various cardiovascular and metabolic disorders such as atherosclerosis, obesity and metabolic syndrome (MS). CVS disease itself is a leading cause of death. Statins reduce plasma lipids and lower the incidence for some of these disorders in $20-40 \%$ individuals, highlighting a need for new approaches to lower plasma lipids. Dietary and endogenous lipids are transported in plasma by lipoproteins made mainly by enterocytes and hepatocytes. Microsomal triglyceride transfer protein (MTP) assists the lipoprotein assembly by interacting and lapidating nascent apolipoprotein $\mathrm{B}$ (apoB) to form precursors of lipids [170,171]. Therefore MTP has been targeted to lower plasma lipids. But these attempts have been hindered as MTP inhibitors cause steatosis and increase plasma transaminases AST/ALT. Hence Soh et al show that miR-30c interacts with the 3'UTR of the MTP mRNA and induce degradation leading to reductions in its activity and media apoB. Further miR 30c reduces hyperlipidemia and atherosclerosis in western fed mice by decreasing lipid synthesis and secretion of triglyceride-rich apoB containing lipoproteins. Therefore miR30c coordinately reduces lipid biosynthesis and lipoprotein secretion to control hepatic and plasma lipidsand might be useful in treating hyperlipidemias and associated disorders [172].

\section{Role of dysregulated cholesterolmetabolism in brain}

Dysregulation of cholesterol metabolism in the brain has been associated with many neurodegenerative disorders, such as Alzheimers disease, Nieman-Pick type C disease, Smith-Lemli-Opitz Syndrome, Huntington's disease and Parkinson's disease. Specifically genes involved in cholesterol biosynthesis (24-dehydrocholesterol reductase DHCR24) and cholesterol efflux (ATP binding cassette transporter 1(ABCA1), and apolipoprotein E (APOE), has been associated with the development of Alzheimer' disease. Indeed APOE was the first gene variation found to increase the risk of Alzheimer's disease and remains the risk gene with the greatest known impact. Mutations in another cholesterol biosynthetic gene, 7-dehyrocholesterol reductase (DHCR7), cause Smith-Lemli-Opitz syndrome and impairment in cellular cholesterol trafficking caused by mutations in the NPC1 protein results in Niemann-Pick type $\mathrm{C}$ disease. Taken together, these findings provide strong evidence that cholesterol metabolism needs to be controlled at very tight levels in the brain. Recent studies have implicated microRNAs as novel regulators of cholesterol metabolism in several tissues. Goedeke et al. reviewed how cholesterol metabolism is regulated by miRNAs and their potential implications in several neurodegenerative disorders e.g., Alzheimers disease and they discussed how antagonizing miRNA expression could be a potential therapy for treating cholesterol related disorders [172]. 


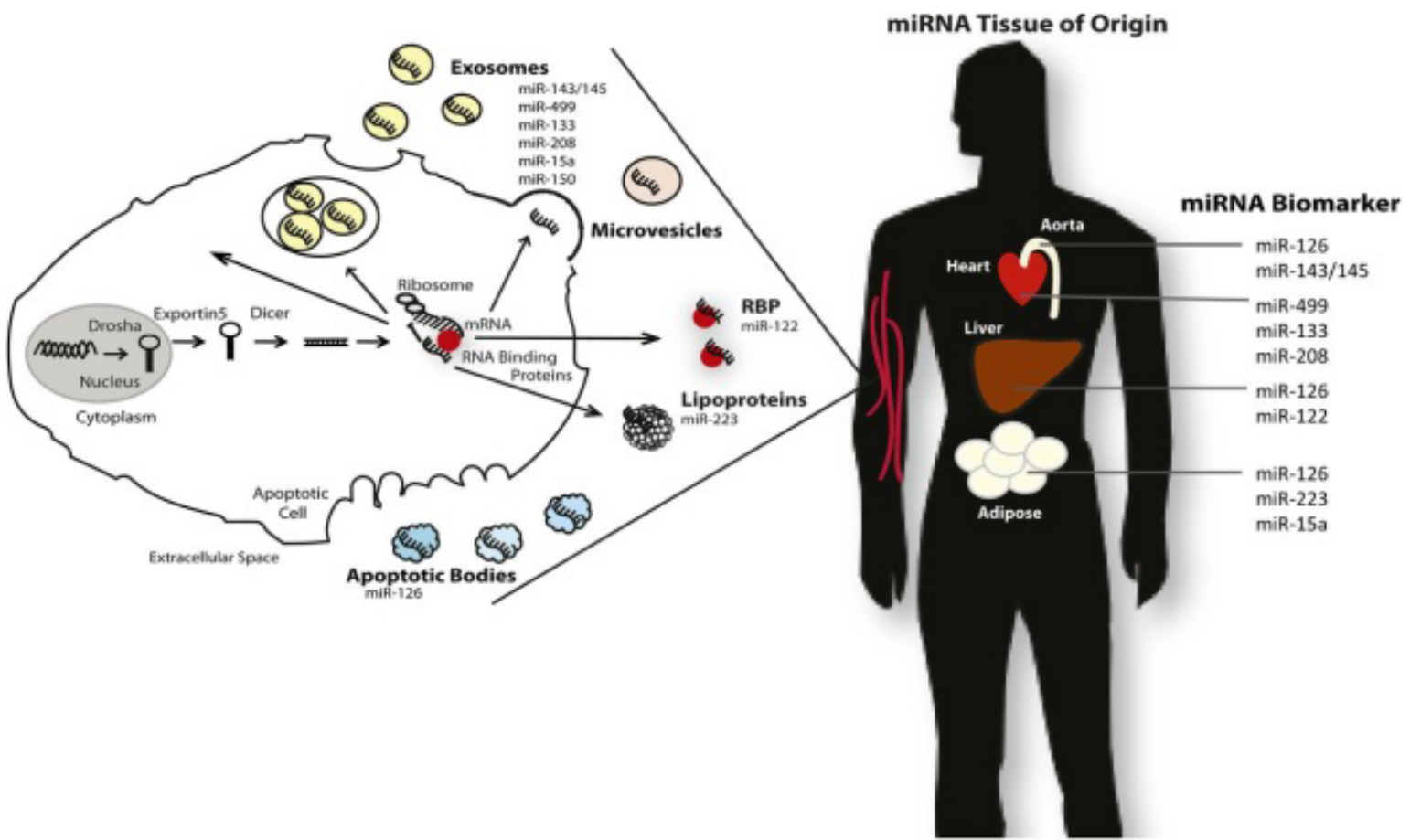

Figure 3: MicroRNAs are secreted into the circulation and are biomarkers for various diseases. MiRNAs are secreted by various lipid containing vesicles including exosomes, microvesicles, and apoptotic bodies and can be found outside of vesicles but beyond to RNA binding proteins (left) specific miRNA that are highlighted as biomarkers are indicated as well as the tissue of origin, potentially where disease is occurring i.e., adipose tissue, liver, heart and aorta (right) [174].

\section{Potential Therapeutic Use}

\section{miRNA's as biomarkers}

With the discovery that miRNA's are found in extracellular space, constitute a form of cell-cell communication and having been found in plasma, urine, saliva and recently been shown to be carried on lipoproteins has increased the complexity of miRNA mediated pathway.This has led to a proposal that circulating miRNA's maybe useful biomarkers of various diseases including cardiovascular diseases, $\mathrm{DM}$, and other terms of dysregulated metabolism. Although the understanding of the cellular machinery responsible for the secretion of miRNA is incomplete it has been demonstrated that miRNA's are packaged into exosomes, microvesicles and apoptotic bodies (Figure 3) $[173,174]$. The excitement for miRNA's as biomarkers is mounting as more and more evidence supports thar noncoding RNA's are actively secreted from diseased tissues, possibly before the onset of overt disease. While caution should be taken in these earlier days, there is little doubt that extracellular miRNA's will hold tremendous potential as both diagnostic and therapeutic agents [175].

\section{Therapeutic uses of AMO'S (antimiRNA oligonucleotides) / LNA'S (locked nucleic acids)}

With recent implications of miRNAs as gene regulatory molecules implicated in pathogenesis of several human diseases e.g., neurodegenerative disorders, cancer, viral and metabolic diseasea. "Silecing" of key miRNAs and replacement of certain tissue specific miRNA whose expression is known to be decreased are potential therapeutic interventions. Techniques can be anti miRNA oligonucleotides (AMO's) to deactivateand silence miRNAs. AMO's are synthetic oligonucleotides that competitively inhibit interaction between miRNAs. Several antisense oligonucleotides that were based on first generationchemical compounds (2'-O-methyl or 2'-O-methoxyethyl) have been extensively evaluated in clinical trials for renal toxicity. While miRNAs whose expression is decreased during disease can be achieved through miRNA mimicry. Plasma viral vectors encoding miRNAs are encouraging strategies to replace miRNA in vivo with good transduction efficiency and minimal toxicity $[175,176]$. To date, the greatest efforts have been made in exploring the potential applications of miRNA therapeutics in cancer and liver disorders. Gain or loss of function of individual miRNAs has been reported in almost every haematological and solid cancer, with therapeutic suppressive effect in tumor cellproliferation, progression and metastasis of tumors [176]. Just as silencing of miR122, which has been proved to regulate cholesterol metabolism and HCV infection can be silenced by intraperitoneal administration of high affinity LNA has resulted in lowering of cholesterol both in mice and non human primates (monkeys) [59,177] and is almost ready for human use [128,178]. Miravirsen is a 15 nucleotide LNA-modified antisense complimentary to and with a high affinity and specificity for 5 ' region of mature miR122. Jansenn et al. have used miravirsen to treat patients with known HCV infection (4 groups in different doses with a placebo group) and despite low numbers and short follow up a minimal insignificant risk of renal toxicity warrants close monitoring and careful selection of patients [127].

\section{Therapeutic potential of lipid metabolism mirnas in atherosclerosis}

Hyperlipidemia is one of the most critical risk factors contributing to atherosclerosis.along with other wellknown factors like obesity, IR and smoking. At present most therapeutic strategies focus on lowering LDL-cholesterol, for e.g., by using a strategywhich has been known to lower patients' mortality. However a more comlex approach focusing 
Citation: Kaur KK, Allahbadia GN, Singh M (2015) An Update on Microrna's and Metabolic Regulation with Future Therapeutic PotentialsRegarding Diagnosis and Treatment of Obesity, Metabolic Syndrome and Other Related Disorders. J Health Med Informat 6: 184. doi: $10.4172 / 2157-7420.1000184$

Page 11 of 16

on the lowering the level of circulating Fatty acids and increasing the levels of HDL is now being investigated. Due to their multitargeting essence, miRNA's may thus become very powerful tools, influencing allstages of the pathogenic processof hyperlipidemia/dyslipidemia and possibly affecting the entire blood lipid spectrum of affected patients. At present, there are two main ways of using miRNAs therapy: the inhibition strategy uses antagomiRs (sequences that bind to target miR and block its function) while replacement therapy uses miRNA mimics [179].

Most of the work in the field of cardiometabolic diseases has so far focused on miR 33 [180-183]. Since the effects of of this miR aremostly proathersclerotic, as described above, antagomiR therapy against miR33 would be a reasonable choice [184-187]. Short term treatment with miR 33 inhibitors markedly increase plasma HDL-C levels and chances of regression of atherosclerosis [133-137,143]. However the efficacy of antimiR therapy on the progression of atherosclerosis is controversial $[180,182,184]$.

A number of studies have recently identified miR33 as a potential therapeutic target for treating cardiometabolic disorders including atherosclerosis and MS $[143,180,183]$. These reports demonstrate that miR silencing in mice results in increased circulating HDL-C and bile secretion, thereby enhancing mobilization of sterols accumulated from the peripheral tissue through the reverse cholesterol transport (RCT) pathway $[139,144]$. Since increased RCT correlates inversely with the incidence of coronary artery disease, several groups studied the efficacy of antimiR33 therapy during the progression and regression of atherosclerosis. In the single -regression study published, Moore's group demonstrated that 4 -week treatment with 2 'F/MOE antimiR33 Oligo nucleotides accelerated the regression of atherosclerosis in Ldlr-/1-micewith established atherosclerotic plaques [143]. The atherosclerosis progression studies, however have opposite outcomes, while Baldan's group found that a 12-week anti-miR33 therapy failed to sustain increased circulating HDL-C and prevent atherogenesis [182], they reported that miR33 ASO successfully reduced the progression of atherosclerosis, despite the insignificant alterations of HDL-C levels [183]. Thediscrepancies observed between both atherosclerosis progression studies may be explained by the different oligonucleotide chemistry and slightly different diets used. However the fact that the genetic ablation of miR33 protects against the progression of atherosclerosis in apoE-/-mice suggests that longterm antimiR33 therapy should be beneficial for treating atherosclerotic vascular disease [180].The most remarkable difference between the miR-33 antisense therapy and genetic studies is that the ability to increase plasma HDL-C levels was lost in the two progression studies, using antimiR33 Oligos, while miR33-/-apoE-/-mice still had increased circulating HDL-C. These results suggest that antimiR ASO delivery may not completely inhibit miR-33 activity in the liver. Goedebe et al. used a combination of bioinformatics approaches (targetscan, pictar, and mirwalk) to identify potential novel targets of miR 33 to determine whether miR 33 directly regulates genes involved in fatty acid and cholesterol metabolism. They found that miR33 had predicted binding sites in the 3'UTR of SREBP1 and HMGCR. Both predicted binding sites are conserved in mammals. On cloning the 3'UTR of HMGCR and SREBP1 into luciferase transporter plasmids, they found miR33 fails to repress the 3'UTR of both genes, suggesting that miR 33 does not regulate their expression directly. On long term therapeutic silencing of miR33 they found increase in circulating triglycerides (TG) levels and lipid accumulation in the liver. These adverse effects were only found in mice fed HFD. Mechanistically they demonstrated that chronic inhibitionof miR 33 increases the expression of genes involved in FA synthesis like ACC. FAS in the livers of mice treated withmiR 33 antisense oligonucleotides. They also reported that antimiR33 therapy enhances the expression of nuclear transcription Y subnunit gamma (NFYC), a transcriptional regulator required for DNA binding and full transcriptional activation of SREBP response genes, including ACC and FAS. Taken together these results suggest that persistent inhibition of miR33 when mice are fed a HFD might cause deleterious effects such as moderate hepatic steatosisand hypertriglyceridemia. They concluded that these unexpected findings highlight the importance of assessing the chronic inhibition of miR 33 in non human primates before we can translate therapy to humans [185].

\section{Conclusions}

Thusin this review we have tried to summarize how miR's have a role in the current known aetiopathogenetic factors of obesity at different age groups starting with infancy where how bottlesfeeding has become an important cause of increased obesity in early infancy and role of miR 155 in development of Treg cells and its relation besides bifidobecteria, mTORC1 in development of allergic disorders and obesity. Then in early childhood the role of miR27a and 130a is emphasized in the PPAR gamma and role in adipocyte differentiation and Treg cell differentiation besides role of macrophages in development of inflammation and correlation with chemokine CCL2 monocytes [186,187] and importance of miR223 in inflammation and chemokine is emphasized [187], not only do miR'S affect preadipocyte conversion but also affect macrophage conversion and then HDL'S are carriers and transport miR223 and help explaining recent involvement of HDL in innate and adaptive immunity. Further the complications are interlinked e.g., miR 143/145 cluster has a role in preadipocyte differentiation, VSMC proliferation which is used therapeutically e.g., in cases of restenosis and further has been used for breast cancer as well [188]. Although miR33 offered a lot of promise to start with, still its use in human beings can not be offered with the results ofchronic use by Goedecke [183]. The process of miR's not only helps us to understand the pathophysiology of lipid metaboilism and its correlation in the development of obesity but helps us to use circulating miR's as biomarkers for disease process and then to further get pharmacological strategies to treat obesity and related disorders. Further two stable nucleic acid lipid particle ( SNALP)formulated siRNA drugs were designed to treat high levels of blood cholesterol or hypercholesterolemia, though TKM-ApoB (Tekmira) targeted ApoB [189]; while ALN-PCS (Alnylam) targeted proprotein convertase subtilisn/kexin type 9 (PCSK9) [188]. Both drugs were tested in Phase 1 clinical trials and were determined to be safe and well tolerated with no serious adverse events associated with drug administration. Polymer-based nanomedicine,an arena that entails the use of polymeric nanoparticles, polymer micelles, dendrimers, polymersomes, polyplexes, polymer-lipid hybrid systemsand polymerdrug/protein conjugates has greatly revolutionized the therapy of cancer by surmounting the current limitations in conventional chemotherapy, which include undesirable biodistribution, cancer cell drug resistanceand severe systemic side effects and in combination of various miRNA and siRNA can achieve efficient cancer chemotherapy [189].

\section{References}

1. Ambros $\vee(2004)$ The functions of animal microRNAs. Nature 431: 350-355.

2. Kozomara A, Griffiths-Jones S (2011) miRBase: integrating microRNA annotation and deep-sequencing data. Nucleic Acids Res 39: D152-157.

3. Deiters A (2010) Small molecule modifiers of the microRNA and RNA interference pathway. AAPS J 12: 51-60. 
Citation: Kaur KK, Allahbadia GN, Singh M (2015) An Update on Microrna's and Metabolic Regulation with Future Therapeutic PotentialsRegarding Diagnosis and Treatment of Obesity, Metabolic Syndrome and Other Related Disorders. J Health Med Informat 6: 184. doi: $10.4172 / 2157-7420.1000184$

Page 12 of 16

4. Bartel DP (2009) MicroRNAs: target recognition and regulatory functions. Cell 136: 215-233.

5. Chekulaeva M, Filipowicz W (2009) Mechanisms of miRNA-mediated posttranscriptional regulation in animal cells. Curr Opin Cell Biol 21: 452-460.

6. Bala S, Marcos M, Szabo G (2009) Emerging role of microRNAs in liver diseases. World J Gastroenterol 15: 5633-5640.

7. Divakar V, Mann DL (2008)The emerging role of microRNAs in cardiac remodeling and heart failure. Circ Res 103: 513-521.

8. Gregory RI, Chendrimada TP, Cooch N, Shiekhattar R (2005) Human RISC couples microRNA biogenesis and posttranscriptional gene silencing. Cell 123 $631-640$.

9. Hammond SM, Boettcher S, Caudy AA, Kobayashi R, Hannon GJ (2001) Argonaute2, a link between genetic and biochemical analyses of RNAi. Science 293: $1146-1150$

10. Preall JB, Sontheimer EJ (2005) RNAi: RISC gets loaded. Cell 123: 543-545.

11. Schwarz DS, Hutvágner G, Du T, Xu Z, Aronin N, et al. (2003) Asymmetry in the assembly of the RNAi enzyme complex. Cell 115: 199-208.

12. Lingel A, Simon B, Izaurralde E, Sattler M (2003) Structure and nucleic-acid binding of the Drosophila Argonaute 2 PAZ domain. Nature 426: 465-469.

13. Forman JJ, Legesse-Miller A, Coller HA (2008) A search for conserved sequences in coding regions reveals that the let-7 microRNA targets Dicer within its coding sequence. Proc Natl Acad Sci U S A 105: 14879-14884.

14. Nur SM, Hasan MA, Amin MA, Hossain MA, Shamin T (2014) Design of potentia RNAi (miRNA and siRNA) molecules for middle east respiratory syndrome corona virus (MERS-CoV) gene silencing by computational methods.

15. Hoque KM, Azim MF, Mia MR, Kayesh R, Ali MH, et al. (2012) Design of potential siRNA molecules for $T$ antigen gene silencing of Merkel Cell Polyomavirus. Bioinformation 8: 924-930.

16. Nur SM, Amin M, Alam R, Hasan MA, Hossain MA, et al. (2013) An in silico approach to design potential siRNA molecules for ICP22 (US1) gene silencing of different strains of human herpes simplex 1. J Young Pharm 5: 46-49.

17. Zhou J, Shum KT, Burnett JC, Rossi JJ (2013) Nanoparticle-Based Delivery of RNAi Therapeutics: Progress and Challenges. Pharmaceuticals (Basel) 6 : 85-107.

18. Landesman Y, Svrziikapa N, Cognetta A, Zhang X, Bettencourt BR, et al. (2010) In vivo quantification of formulated and chemically modified small interfering RNA by heating in Triton quantitative reverse transcription polymerase chain reaction.(HIT-QRT-PCR). Silence 1: 16.

19. Long L, Wang W, Cai XD, Cheng D, Shuai X, et al. (2014) PinX1-siRNA/mPEGPEI-SPION combined with doxorubicin enhances the inhibition of glioma growth. Exp Ther Med 7: 1170-1176.

20. Dou S, Yang $X Z$, Xiong MH, Sun CY, Yao YD, et al. (2014) ScFv-decorated PEG-PLA-based nanoparticles for enhanced siRNA delivery to Her2 ${ }^{+}$breas cancer. Adv Healthc Mater 3: 1792-1803.

21. Tseng YH, Cypess AM, Kahn CR (2010) Cellular bioenergetics as a target for obesity therapy. Nat Rev Drug Discov 9: 465-482.

22. Romeo GR, Lee J, Shoelson SE (2012) Metabolic syndrome, insulin resistance, and roles of inflammation--mechanisms and therapeutic targets. Arterioscler Thromb Vasc Biol 32: 1771-1776.

23. Odegaard JI, Chawla A (2013) Pleiotropic actions of insulin resistance and inflammation in metabolic homeostasis. Science 339: 172-177.

24. Lee BC, Lee J (2014) Cellular and molecular players in adipose tissue inflammation in the development of obesity-induced insulin resistance. Biochim Biophys Acta 1842: 446-462

25. Alexander R, Lodish H, Sun L (2011) MicroRNAs in adipogenesis and as therapeutic targets for obesity. Expert Opin Ther Targets 15: 623-636.

26. Son YH, Ka S, Kim AY, Kim JB (2014) Regulation of Adipocyte Differentiation via MicroRNAs. Endocrinol Metab (Seoul) 29: 122-135.

27. Chen C, Peng Y, Peng Y, Peng J, Jiang S (2014) miR-135a-5p inhibits 3T3-L1 adipogenesis through activation of canonical Wnt/ $\beta$-catenin signaling. $\mathrm{J}$ Mol Endocrinol 52: 311-320.

28. Yang L, Shi CM, Chen L, Pang LX, Xu GF, et al. (2014) The biological effects of hsa-miR-1908 in human adipocytes. Mol Biol Rep.
29. Cannon B, Nedergaard J (2004) Brown adipose tissue: function and physiological significance. Physiol Rev 84: 277-359.

30. Lonear D, Afzelius BA, Cannon B (1988) Epididymal white adipose tissue afte cold stress in rats. L Nonmitichondrial changes. J Ultrastruct Mol Struct Res 101: 109-122.

31. Waldén TB, Hansen IR, Timmons JA, Cannon B, Nedergaard J (2012) Recruited vs. non-recruited molecular signatures of brown, "brite," and white adipose tissues. Am J Physiol Endocrinol Metab 302: E19-31.

32. Petrovic N, Walden TB, Shabalina IG, Timmons JA, Cannon B, et al. (2010) Chronic peroxisome proliferator-activated receptor gamma (PPARgamma) activation of epididymally derived white adipocyte cultures reveals a population of thermogenically competent, UCP1-containing adipocytes molecularly distinct from classic brown adipocytes. J Biol Chem 285: 7153-7164.

33. Pisani DF, Djedaini M, Beranger GE, Elabd C, Scheideler M, et al. (2011) Differentiation of Human Adipose-Derived Stem Cells into "Brite" (Brown-inWhite) Adipocytes. Front Endocrinol (Lausanne) 2: 87

34. Feldmann HM, Golozoubova V, Cannon B, Nedergaard J (2009) UCP1 ablation induces obesity and abolishes diet-induced thermogenesis in mice exempt from thermal stress by living at thermoneutrality. Cell Metab 9: 203-209.

35. Rothwell NJ, Stock MJ (1983) Luxuskonsumption, diet-induced thermogenesis and brown fat: the case in favour. Clin Sci (Lond) 64: 19-23.

36. Nedergaard J, Cannon B (2010) The changed metabolic world with human brown adipose tissue: therapeutic visions. Cell Metab 11: 268-272.

37. Karbiener M, Scheideler M (2014) MicroRNA Functions in Brite/Brown Fat Novel Perspectives towards Anti-Obesity Strategies. Comput Struct Biotechno J 11: 101-105.

38. Chen Y, Siegel F, Kipschull S, Haas B, Fröhlich H, et al. (2013) miR-155 regulates differentiation of brown and beige adipocytes via a bistable circuit. Nat Commun 4: 1769 .

39. Sun L, Trajkovski M (2014) MiR-27 orchestrates the transcriptional regulation of brown adipogenesis. Metabolism 63: 272-282.

40. Wu Y, Zuo J, Zhang Y, Xie Y, Hu F, et al. (2013) Identification of miR-106b-93 as a negative regulator of brown adipocyte differentiation. Biochem Biophys Res Commun 438: 575-580.

41. Serino M, Menghini R, Fiorentino L, Amoruso R, Mauriello A, et al. (2007) Mice heterozygous for tumor necrosis factor-alpha converting enzyme are protected from obesity-induced insulin resistance and diabetes. Diabetes 56: 2541-2546.

42. Gelling RW, Yan W, Al-Noori S, Pardini A, Morton GJ, et al. (2008) Deficiency of TNFalpha converting enzyme (TACE/ADAM17) causes a lean, hypermetabolic phenotype in mice. Endocrinology 149: 6053-6064

43. Cipolletta D, Feuerer M, Li A, Kamei N, Lee J, et al. (2012) PPAR-y is a majo driver of the accumulation and phenotype of adipose tissue Treg cells. Nature 486: 549-553.

44. Ortega FJ, Serrano M, Rodriquez-Cuenca S, Moreno-Navarrele JM, GomezSerrano M, et al.(2014) Transducin like enhancer of split3(TLE3) in adipose tissue is increased in situations characterizedby decreased PPAR-y gene expression.

45. Kim SY, Kim AY, Lee HW, Son YH, Lee GY, et al. (2010) miR-27a is a negative regulator of adipocyte differentiation via suppressing PPAR gamma expression. Biochem Biophys Res Commun 392: 323-328.

46. Lee EK, Lee MJ, Abdelmohsen K, Kim W, Kim MM, et al. (2011) miR-130 suppresses adipogenesis by inhibiting peroxisome proliferator-activated receptor gamma expression. Mol Cell Biol 31: 626-638.

47. Hata T, Murakami K, Nakatani H, Yamamoto Y, Matsuda T, et al. (2010) Isolation of bovine milk-derived microvesicles carrying mRNAs and microRNAs. Biochem Biophys Res Commun 396: 528-533.

48. Chen X, Gao C, Li H, Huang L, Sun Q, et al. (2010) Identification and characterization of microRNAs in raw milk during different periods of lactation commercial fluid, and powdered milk products. Cell Res 20: 1128-1137.

49. Izumi H, Kosaka N, Shimizu T, Sekine K, Ochiya T, et al. (2012) Bovine milk contains microRNA and messenger RNA that are stable under degradative conditions. J Dairy Sci 95: 4831-4841.

50. Admyre C, Johansson SM, Qazi KR, Filén JJ, Lahesmaa R, et al. (2007) Exosomes with immune modulatory features are present in human breast milk. J Immunol 179: 1969-1978. 
Citation: Kaur KK, Allahbadia GN, Singh M (2015) An Update on Microrna's and Metabolic Regulation with Future Therapeutic PotentialsRegarding Diagnosis and Treatment of Obesity, Metabolic Syndrome and Other Related Disorders. J Health Med Informat 6: 184. doi: $10.4172 / 2157-7420.1000184$

Page 13 of 16

51. Kosaka N, Izumi H, Sekine K, Ochiya T (2010) microRNA as a new immuneregulatory agent in breast milk. Silence $1: 7$.

52. Sun Q, Chen X, Yu J, Zen K, Zhang CY, et al. (2013) Immune modulatory function of abundant immune-related microRNAs in microvesicles from bovine colostrum. Protein Cell 4: 197-210.

53. Munch EM, Harris RA, Mohammad M, Benham AL, Pejerrey SM, et al. (2013) Transcriptome profiling of microRNA by Next-Gen deep sequencing reveals known and novel miRNA species in the lipid fraction of human breast milk. PLoS One 8: e50564.

54. Kohlhaas S, Garden OA, Scudamore C, Turner M, Okkenhaug K, et al. (2009) Cutting edge: the Foxp3 target miR-155 contributes to the development of regulatory T cells. J Immunol 182: 2578-2582.

55. Marson A, Kretschmer K, Frampton GM, Jacobsen ES, Polansky JK, et al. (2007) Foxp3 occupancy and regulation of key target genes during T-cel stimulation. Nature 445: 931-935.

56. Cobb BS, Hertweck A, Smith J, O'Connor E, Graf D, et al. (2006) A role for Dicer in immune regulation. J Exp Med 203: 2519-2527.

57. Zheng Y, Josefowicz SZ, Kas A, Chu TT, Gavin MA, et al. (2007) Genome-wide analysis of Foxp3 target genes in developing and mature regulatory $\mathrm{T}$ cells. Nature 445: 936-940.

58. Lio CW, Hsieh CS (2008) A two-step process for thymic regulatory T cell development. Immunity 28: 100-111.

59. Burchill MA, Yang J, Vang KB, Moon JJ, Chu HH, et al. (2008) Linked T cell receptor and cytokine signaling govern the development of the regulatory $\mathrm{T}$ cell repertoire. Immunity 28: 112-121.

60. Vang KB, Yang J, Mahmud SA, Burchill MA, Vegoe AL, et al. (2008) IL-2, -7, and -15 , but not thymic stromal lymphopoeitin, redundantly govern CD4+Foxp3+ regulatory T cell development. J Immunol 181: 3285-3290.

61. Lu LF, Thai TH, Calado DP, Chaudhry A, Kubo M, et al. (2009) Foxp3dependent microRNA155 confers competitive fitness to regulatory $T$ cells by targeting SOCS1 protein. Immunity 30: 80-91.

62. Melnik BC (2014) The potential mechanistic link between allergy and obesity development and infant formula feeding. Allergy Asthma Clin Immunol 10: 37.

63. Landgraf K, Rockstroh D, Wagner IV, Weise S, Tauscher R, et al.(2015) Evidence of early alterations in Adipose tissue biology and function and its association with obesity-Related Inflammation and Insulin Resistance in children. Diabetes 64: (p1-13).

64. Prats-Puig A, Ortega FJ, Mercader JM, Moreno-Navarrete JM, Moreno M, et al. (2013) Changes in circulating microRNAs are associated with childhood obesity. J Clin Endocrinol Metab 98: E1655-1660.

65. Rottiers V, Naar AM (2012) MicroRNAs in metabolism and metabolic disorders Nat Rev Mol Cell Biol 13: 239-250.

66. Fernandez-Valverde SL, Taft RJ, Mattick JS (2011) MicroRNAs in I-cell biology, insulin resistance, diabetes and its complications. Diabetes 60: 1825-1831.

67. Diawara MR, Hue C, Wilder SP, Venteclef N, Aron-Wisnewsky J, et al. (2014) Adaptive expression of microRNA-125a in adipose tissue in response to obesity in mice and men. PLoS One 9: e91375.

68. Ortega FJ, Moreno-Navarrete JM, Pardo G, Sabater M, Hummel M, et al (2010) MiRNA expression profile of human subcutaneous adipose and during adipocyte differentiation. PLoS One 5: e9022.

69. Klöting N, Berthold S, Kovacs P, Schön MR, Fasshauer M, et al. (2009) MicroRNA expression in human omental and subcutaneous adipose tissue. PLoS One 4: e4699.

70. Kim C, Lee H, Cho YM, Kwon OJ, Kim W, et al. (2013) TNFa- inuced miR130 resulte in adipocyte dysfunction during obesity related inflammation. FEBS Lett 587: 3853-3858

71. Shi C, Zhu L, Chen X, Gu N, Chen L, et al. (2014) IL-6an TNFa-Induced Obesity "Related Inflammatory Response through transcriptional regulation of miR146b. Interferon Cytokine Res 34: 342-348.

72. Xu G, Shi C, Ji C, Song G, Chen L, et al. (2014) Expression of microRNA$26 \mathrm{~b}$, an obesity-related microRNA, is regulated by free fatty acids, glucose, dexamethasone and growth hormone in human adipocytes. Mol Med Rep 10: 223-228
73. Funahashi T, Nakamura T, Shimomura I, Maeda K, Kuriyama H, et al. (1999) Role of adipocytokines on the pathogenesis of atherosclerosis in viscera obesity. Intern Med 38: 202-206.

74. Matsuzawa Y, Funahashi T, Nakamura T (2002) Molecular mechanism of vascular disease in metabolic syndrome $X$. J Diabetes Complications 16: 17 18.

75. Kershaw EE, Flier JS (2004) Adipose tissue as an endocrine organ. J Clin Endocrinol Metab 89: 2548-2556.

76. Gnacinska M, Malgorzewicz S, Stojek M, Lysiak SW, Sworczak K (2009) Role of adipokines in complications related to obesity: a review. Adv Med Sci 54 150-157.

77. Viesti A Collares $R$, Salgado $W$ Jr, Pretti da Cunha Tirapelli D, dos Santos JS (2014) The expression of LEP, LEPR, IGF1 and IL10 in obesity and the relationship with microRNAs. PLoS One 9: e93512.

78. Ortega FJ, Fernández-Real JM (2013) Inflammation in adipose tissue and fatty acid anabolism: when enough is enough! Horm Metab Res 45: 1009-1019.

79. Chan SY, Loscalzo J (2010) MicroRNA-210: a unique and pleiotropic hypoxamir. Cell Cycle 9: 1072-1083.

80. Zhang K, Kaufman RJ (2008) From endoplasmic-reticulum stress to the inflammatory response. Nature 454: 455-462.

81. Groenendyk J, Peng Z, Dudek E, Fan X, Mizianty MJ, et al. (2014) Interplay between the oxidoreductase PDIA6 and microRNA-322 controls the response to disrupted endoplasmic reticulum calcium homeostasis. Sci Signal 7: ra54.

82. Tu BP, Weissmann NT,Shimomura I, Maeda K, Kuriyama H et al. (1999) Role of adiponecytokines in the pathogenesis of atherosclerosis in visceral obesity Intern Med 38: 202-206.

83. Haynes CM, Titus EA, Cooper AA (2004) Degradation of misfolded proteins prevents ER-derived oxidative stress and cell death. Mol Cell 15: 767-776.

84. Parra P, Serra F, Palou A (2010) Expression of adipose microRNAs is sensitive to dietary conjugated linoleic acid treatment in mice. PLoS One 5: e13005.

85. Heneghan HM, Miller N, McAnena OJ, O’Brien T, Kerin MJ (2011) Differential miRNA expression in omental adipose tissue and in the circulation of obese patients identifies novel metabolic biomarkers. J Clin Endocrinol Metab 96: E846-850.

86. Strum JC, Johnson JH, Ward J, Xie H, Feild J, et al. (2009) MicroRNA 132 regulates nutritional stress-induced chemokine production through repression of SirT1. Mol Endocrinol 23: 1876-1884.

87. Zhuang G, Meng C, Guo X, Cheruku PS, Shi L, et al. (2012) A novel regulato of macrophage activation: miR-223 in obesity-associated adipose tissue inflammation. Circulation 125: 2892-2903.

88. Qi J, Qiao Y, Wang P, Li S, Zhao W, et al. (2012) microRNA-210 negatively regulates LPS-induced production of proinflammatory cytokines by targeting NF-kB1 in murine macrophages. FEBS Lett 586: 1201-1207.

89. Graff JW, Dickson AM, Clay G, McCaffrey AP, Wilson ME (2012) Identifying functional microRNAs in macrophages with polarized phenotypes. J Biol Chem 287: 21816-21825.

90. O'Neill LA, Sheedy FJ, McCoy CE (2011) MicroRNAs: the fine-tuners of Tolllike receptor signalling. Nat Rev Immunol 11: 163-175.

91. Androulidaki A, lliopoulos D, Arranz A, Doxaki C, Schworer S, et al. (2009) The kinase Akt1 controls macrophage response to lipopolysaccharide by regulating microRNAs. Immunity 31: 220-231.

92. Ge Q, Gérard J, Noël L, Scroyen I, Brichard SM (2012) MicroRNAs regulated by adiponectin as novel targets for controlling adipose tissue inflammation. Endocrinology 153: 5285-5296.

93. Ishida M, Shimabukuro M, Yagi S, Nishimoto S, Kozuka C, et al. (2014) MicroRNA-378 regulates adiponectin expression in adipose tissue: a new plausible mechanism. PLoS One 9: e111537.

94. Arner E, Mejhert N, Kulyté A, Balwierz PJ, Pachkov M, et al. (2012) Adipose tissue microRNAs as regulators of CCL2 production in human obesity. Diabetes 61: 1986-1993.

95. Ortega FJ, Mercader JM, Catalán V, Moreno-Navarrete JM, Pueyo N, et al (2013) Targeting the circulating microRNA signature of obesity. Clin Chem 59 781-792. 
Citation: Kaur KK, Allahbadia GN, Singh M (2015) An Update on Microrna's and Metabolic Regulation with Future Therapeutic PotentialsRegarding Diagnosis and Treatment of Obesity, Metabolic Syndrome and Other Related Disorders. J Health Med Informat 6: 184. doi: $10.4172 / 2157-7420.1000184$

Page 14 of 16

96. Hilton C, Karpe $F(2013)$ Circulating microRNAs: what is their relevance? Clin Chem 59: 729-731.

97. Poste G (2011) Bring on the biomarkers. Nature 469: 156-157.

98. Fernández-Real JM, Pickup JC (2012) Innate immunity, insulin resistance and type 2 diabetes. Diabetologia 55: 273-278.

99. Herrera BM, Lockstone HE, Taylor JM, Ria M, Barrett A, et al. (2010) Global microRNA expression profiles in insulin target tissues in a spontaneous rat model of type 2 diabetes. Diabetologia 53: 1099-1109.

100.Lynn FC (2009) Meta-regulation: microRNA regulation of glucose and lipid metabolism. Trends Endocrinol Metab 20: 452-459.

101. Kosaka N, Iguchi H, Ochiya T (2010) Circulating microRNA in body fluid: a new potential biomarker for cancer diagnosis and prognosis. Cancer Sci 101 2087-2092.

102.Zampetaki A, Willeit P, Drozdov I, Kiechl S, Mayr M (2012) Profiling of circulating microRNAs: from single biomarkers to re-wired networks. Cardiovasc Res 93: 555-562.

103. Vickers KC, Palmisano BT, Shoucri BM, Shamburek RD, Remaley AT (2011) MicroRNAs are transported in plasma and delivered to recipient cells by highdensity lipoproteins. Nat Cell Biol 13: 423-433.

104. Turchinovich A, Weiz L, Langheinz A, Burwinkel B (2011) Characterization of extracellular circulating microRNA. Nucleic Acids Res 39: 7223-7233.

105.Zhu H, Fan GC (2011) Extracellular/circulating microRNAs and their potentia role in cardiovascular disease. Am J Cardiovasc Dis 1: 138-149.

106. Mayr M, Zampetaki A, Willeit P, Willeit J, Kiechl S (2013) MicroRNAs within the continuum of postgenomics biomarker discovery. Arterioscler Thromb Vasc Biol 33: 206-214.

107.Zampetaki A, Kiechl S, Drozdov I, Willeit P, Mayr U, et al. (2010) Plasma microRNA profiling reveals loss of endothelial miR-126 and other microRNAs in type 2 diabetes. Circ Res 107: 810-817.

108. Guay C, Regazzi R (2013) Circulating microRNAs as novel biomarkers for diabetes mellitus. Nat Rev Endocrinol 9: 513-521.

109. Guay C, Roggli E, Nesca V, Jacovetti C, Regazzi R (2011) Diabetes mellitus, a microRNA-related disease? Transl Res 157: 253-264.

110. Karczewska-KM, Kowalska I, Nikolajuk A, Adamska A, Zieli A, et al. (2012) Circulating brain-derived neurotrophic factor concentration is downregulated by intralipid/heparin infusion or high-fat meal in young healthy male subjects. Diabetes Care 35: 358-362.

111. Ortega FJ, Mercader JM, Moreno-Navarrete JM, Rovira O, Guerra E, et al. (2014) Profiling of circulating microRNAs reveals common microRNAs linked to type 2 diabetes that change with insulin sensitization. Diabetes Care 37: $1375-1383$.

112. Kredo-Russo S, Mandelbaum AD, Ness A, Alon I, Lennox KA, et al. (2012) Pancreas-enriched miRNA refines endocrine cell differentiation. Development 139: 3021-3031

113. Leroith D (2014) microRNAs: what the clinician should know about this new frontier. Diabetes Care 37: 1176-1177.

114. Cefalu WT, Hu FB (2004) Role of chromium in human health and in diabetes. Diabetes Care 27: 2741-2751.

115. Zhang Q, Xiao X, Li M, Li W, Yu M, et al. (2014) miR-375 and miR-30d in the effect of chromium-containing Chinese medicine moderating glucose metabolism. J Diabetes Res 2014: 862473

116. Brown MS, Goldstein JL (1997) The SREBP pathway: regulation of cholestero metabolism by proteolysis of a membrane-bound transcription factor. Cell 89 : 331-340.

117. Horton JD, Goldstein JL, Brown MS (2002) SREBPs: activators of the complete program of cholesterol and fatty acid synthesis in the liver. J Clin Invest 109: 1125-1131.

118. Osborne TF (2000) Sterol regulatory element-binding proteins (SREBPs): key regulators of nutritional homeostasis and insulin action. J Biol Chem 275 : 32379-32382.

119. Peet DJ, Janowski BA, Mangelsdorf DJ (1998) The LXRs: a new class of oxysterol receptors. Curr Opin Genet Dev 8: 571-575.
120. Tontonoz P, Mangelsdorf DJ (2003) Liver X receptor signaling pathways in cardiovascular disease. Mol Endocrinol 17: 985-993.

121. Repa JJ, Liang G, Ou J, Bashmakov Y, Lobaccaro JM, et al. (2000) Regulation of mouse sterol regulatory element-binding protein-1c gene (SREBP-1c) by oxysterol receptors, LXR alpha and LXR beta. Genes Dev 14: 2819-2830.

122. Peet DJ, Turley SD, Ma W, Janowski BA, Lobaccaro JM, et al. (1998) Cholesterol and bile acid metabolism are impaired in mice lacking the nuclear oxysterol receptor LXR alpha. Cell 93: 693-704.

123. Lagos-QM, Rauhut R, Yalcin A, Meyer J, Lendeckel W, et al. (2002) Identification of tissue-specific microRNAs from mouse. Curr Biol 12: 735-739.

124. Elmén J, Lindow M, Schütz S, Lawrence M, Petri A, et al. (2008) LNA-mediated microRNA silencing in non-human primates. Nature 452: 896-899.

125. Esau C, Davis S, Murray SF, Yu XX, Pandey SK, et al. (2006) miR-122 regulation of lipid metabolism revealed by in vivo antisense targeting. Cell Metab 3: 87-98.

126. Lanford RE, Hildebrandt-Eriksen ES, Petri A, Persson R, Lindow M, et al. (2010) Therapeutic silencing of microRNA-122 in primates with chronic hepatitis C virus infection. Science 327: 198-201.

127. Janssen HL, Reesink HW, Lawitz EJ, Zeuzem S, Rodriguez-Torres M, et al (2013) Treatment of HCV infection by targeting microRNA. N Engl J Med 368: 1685-1694.

128. Hsu SH, Wang B, Kota J, Yu J, Costinean S, et al. (2012) Essential metabolic anti-inflammatory, and anti-tumorigenic functions of miR-122 in liver. J Clin Invest 122: 2871-2883.

129. Tsai WC, Hsu SD, Hsu CS, Lai TC, Chen SJ, et al (2012) MicroRNA-122 plays a critical role in liver homeostasis and hepatocarcinogenesis. J Clin Invest 122: 2884-2897.

130. lliopoulos D, Drosatos K, Hiyama Y, Goldberg IJ, Zannis VI (2010) MicroRNA-370 controls the expression of microRNA-122 and Cpt1alpha and affects lipid metabolism. J Lipid Res 51: 1513-1523.

131. Gerin I, Bommer GT, McCoin CS, Sousa KM, Krishnan V, et al. (2010) Roles for miRNA-378/378* in adipocyte gene expression and lipogenesis. Am J Physiol Endocrinol Metab 299: E198-206.

132. Marquart TJ, Allen RM, Ory DS, Baldán A (2010) miR-33 links SREBP-2 induction to repression of sterol transporters. Proc Natl Acad Sci U S A 107: 12228-12232.

133. Najafi-Shoushtari SH, Kristo F, Li Y, Shioda T, Cohen DE, et al. (2010) MicroRNA-33 and the SREBP host genes cooperate to control cholesterol homeostasis. Science 328: 1566-1569.

134. Rayner KJ, Suárez Y, Dávalos A, Parathath S, Fitzgerald ML, et al. (2010) MiR-33 contributes to the regulation of cholesterol homeostasis. Science 328 : 1570-1573.

135.Dávalos A, Goedeke L, Smibert P, Ramírez CM, Warrier NP, et al. (2011) $\mathrm{miR}-33 \mathrm{a} / \mathrm{b}$ contribute to the regulation of fatty acid metabolism and insulin signaling. Proc Natl Acad Sci U S A 108: 9232-9237.

136. Gerin I, Clerbaux LA, Haumont O, Lanthier N, Das AK, et al. (2010) Expression of miR-33 from an SREBP2 intron inhibits cholesterol export and fatty acid oxidation. J Biol Chem 285: 33652-33661.

137. Goedeke L, Vales-Lara FM, Fenstermaker M, Cirera-Salinas D, ChamorroJorganes A, et al. (2013) A regulatory role for microRNA 33* in controlling lipid metabolism gene expression. Mol Cell Biol 33: 2339-2352.

138. Allen RM, Marquart TJ, Albert CJ, Suchy FJ, Wang DQ, et al. (2012) miR-33 controls the expression of biliary transporters, and mediates statin- and dietinduced hepatotoxicity. EMBO Mol Med 4: 882-895.

139. Ramírez CM, Goedeke L, Rotllan N, Yoon JH, Cirera-Salinas D, et al. (2013) MicroRNA 33 regulates glucose metabolism. Mol Cell Biol 33: 2891-2902.

140. Musso G, Gambino R, Cassader M (2013) Cholesterol metabolism and the pathogenesis of non-alcoholic steatohepatitis. Prog Lipid Res 52: 175-191.

141. Fernández-Hernando $C$, Suárez Y, Rayner KJ, Moore KJ (2011) MicroRNAs in lipid metabolism. Curr Opin Lipidol 22: 86-92.

142. Rayner KJ, Sheedy FJ, Esau CC, Hussain FN, Temel RE, et al. (2011) Antagonism of miR-33 in mice promotes reverse cholesterol transport and regression of atherosclerosis. J Clin Invest 121: 2921-2931. 
Citation: Kaur KK, Allahbadia GN, Singh M (2015) An Update on Microrna's and Metabolic Regulation with Future Therapeutic PotentialsRegarding Diagnosis and Treatment of Obesity, Metabolic Syndrome and Other Related Disorders. J Health Med Informat 6: 184. doi: $10.4172 / 2157-7420.1000184$

143. Horie T, Ono K, Horiguchi M, Nishi $\mathrm{H}$, Nakamura T, et al. (2010) MicroRNA-33 encoded by an intron of sterol regulatory element-binding protein 2 (Srebp2) regulates HDL in vivo. Proc Natl Acad Sci U S A 107: 17321-17326.

144. Cirera-Salinas D, Pauta M, Allen RM, Salerno AG, Ramírez CM, et al. (2012) Mir-33 regulates cell proliferation and cell cycle progression. Cell Cycle 11: 922-933.

145. Cordes KR, Sheehy NT, White MP, Berry EC, Morton SU, et al. (2009) miR145 and miR-143 regulate smooth muscle cell fate and plasticity. Nature 460 705-710.

146. Elia L, Quintavalle M, Zhang J, Contu R, Cossu L, et al. (2009) The knockout of miR-143 and -145 alters smooth muscle cell maintenance and vascular homeostasis in mice: correlates with human disease. Cell Death Differ 16 1590-1598.

147.Xin M, Small EM, Sutherland LB, Qi X, McAnally J, et al. (2009) MicroRNAs miR-143 and miR-145 modulate cytoskeletal dynamics and responsiveness of smooth muscle cells to injury. Genes Dev 23: 2166-2178.

148. Cipollone F, Felicioni L, Sarzani R, Ucchino S, Spigonardo F, et al. (2011) A unique microRNA signature associated with plaque instability in humans. Stroke 42: 2556-2563.

149.Esau C, Kang X, Peralta E, Hanson E, Marcusson EG, et al. (2004) MicroRNA-143 regulates adipocyte differentiation. J Biol Chem 279: 52361 52365 .

150.Sala F, Aranda JF, Rotllan N, Ramírez CM, Aryal B, et al. (2014) MiR-143/145 deficiency attenuates the progression of atherosclerosis in Ldlr-/-mice. Thromb Haemost 112: 796-802.

151. Jordan SD, Krüger M, Willmes DM, Redemann N, Wunderlich FT, et al. (2011) Obesity-induced overexpression of miRNA143inhibits insulin "stimulated AKT activation and impairs glucose metabolism. Nature Cell Biology 13: 434-445.

152. Norata GD, Tibolla G, Catapano AL (2013) Gene silencing approaches for the management of dyslipidaemia. Trends Pharmacol Sci 34: 198-205.

153. Norata GD, Ballantyne CM, Catapano AL (2013) New therapeutic principles in dyslipidaemia: focus on LDL and $L p(a)$ lowering drugs. Eur Heart J 34: 17831789.

154. Muthiah M, Islam MA, Chu CS, Hwang JE, Chung IJ, et al. (2014) Substrate mediated delivery of microRNA-145 through a polysorbitol-based osmotically active transporter suppresses smooth muscle cell proliferation: implications for restenosis treatment. J Biomed Nanotechnol 10: 571-579.

155. Sun L, Xie H, Mori MA, Alexander R, Yuan B, et al. (2011) Mir193b-365 is essential for brown fat differentiation. Nat Cell Biol 13: 958-965.

156. Chen T, Huang Z, Wang L, Wang Y, Wu F, et al. (2009) MicroRNA-125a-5p partly regulates the inflammatory response, lipid uptake, and ORP9 expression in oxLDL-stimulated monocyte/macrophages. Cardiovasc Res 83: 131-139.

157. Vickers KC, Shoucri BM, Levin MG, Wu H, Pearson DS, et al. (2013) MicroRNA-27b is a regulatory hub in lipid metabolism and is altered in dyslipidemia. Hepatology 57: 533-542.

158.Lu D, Rhodes DG (2002) Binding of phosphorothioate oligonucleotides to zwitterionic liposomes. Biochim Biophys Acta 1563: 45-52.

159. Trajkovic K, Hsu C, Chiantia S, Rajendran L, Wenzel D, et al. (2008) Ceramide triggers budding of exosome vesicles into multivesicular endosomes. Science 319: $1244-1247$

160.Wagner J, Riwanto M, Besler C, Knau A, Fichtlscherer S, et al. (2013) Characterization of levels and cellular transfer of circulating lipoprotein-bound microRNAs. Arterioscler Thromb Vasc Biol 33: 1392-1400.

161. Norata GD, Pirillo A, Catapano AL (2011) HDLs, immunity, and atherosclerosis. Curr Opin Lipidol 22: 410-416.

162. Norata GD, Pirillo A, Ammirati E, Catapano AL (2012) Emerging role of high density lipoproteins as a player in the immune system. Atherosclerosis 220 : 11-21.

163. Johnnidis JB, Harris MH, Wheeler RT, Stehling-Sun S, Lam MH, et al. (2008) Regulation of progenitor cell proliferation and granulocyte function by microRNA-223. Nature 451: 1125-1129.

164. Tabet F, Vickers KC, Cuesta Torres LF, Wiese CB, Shoucri BM, et al. (2014) HDL-transferred microRNA-223 regulates ICAM-1 expression in endothelial cells. Nat Commun 5: 3292.
165. Barter P, Gotto AM, LaRosa JC, Maroni J, Szarek M, et al. (2007) HDL cholesterol, very low levels of LDL cholesterol, and cardiovascular events. N Engl J Med 357: 1301-1310.

166. Vickers KC, Landstreet SR, Levin MG, Shoucri BM, Toth CL, et al. (2014) MicroRNA-223 coordinates cholesterol homeostasis. Proc Natl Acad Sci U S A 111: 14518-14523.

167. Lakner AM, Bonkovsky HL, Schrum LW (2011) microRNAs: fad or future of liver disease. World J Gastroenterol 17: 2536-2542.

168. Leng RX, Pan HF, Qin WZ, Chen GM, Ye DQ (2011) Role of microRNA-155 in autoimmunity. Cytokine Growth Factor Rev 22: 141-147.

169. Miller AM, Gilchrist DS, Nijjar J, Araldi E, Ramirez CM, et al. (2013) MiR-155 has a protective role in the development of non-alcoholic hepatosteatosis in mice. PLoS One 8: e72324.

170. Hussain MM, Rava P, Walsh M, Rana M, Iqbal J (2012) Multiple functions of microsomal triglyceride transfer protein. Nutr Metab (Lond) 9: 14.

171.Soh J, lqbal J, Queiroz J, Fernandez-Hernando C, Hussain MM (2013) MicroRNA-30c reduces hyperlipidemia and atherosclerosis in mice by decreasing lipid synthesis and lipoprotein secretion. Nat Med 19: 892-900.

172. Goedeke L, Fernández-Hernando C2 (2014) MicroRNAs: a connection between cholesterol metabolism and neurodegeneration. Neurobiol Dis $72 \mathrm{Pt}$ A: $48-53$.

173. Rayner KJ.Hennessy EJ (2013) Extracellular communication via miRNA: lipid particleshave a new message. Jr Lipid Res 54: 1174-1181.

174. Krützfeldt J, Rajewsky N, Braich R, Rajeev KG, Tuschl T, et al. (2005) Silencing of microRNAs in vivo with 'antagomirs'. Nature 438: 685-689.

175. McDermott AM, Heneghan HM, Miller N, Kerin MJ (2011) The therapeutic potential of microRNAs: disease modulators and drug targets. Pharm Res 28 : 3016-3029.

176. Weiler J, Hunziker J, Hall J (2006) Anti-miRNA oligonucleotides (AMOs) ammunition to target miRNAs implicated in human disease? Gene Ther 13: 496-502.

177. Reesink HW, Janssen HLA, Zeuzem S, LawitzE, Rodriques TM, et al.(2012) Final results randomized double blind, placebo controlled safety, antiviral proof of concept study of miravirsen: an oligonucleotide targeting miR122 in treatment naïve patients with genotype 1 chronic $\mathrm{HCV}$ infection.J Hepato Suppl 2: 56: 526

178. Soriano A, Jubierre L, Almazán-Moga A, Molist C, Roma J, et al. (2013) microRNAs as pharmacological targets in cancer. Pharmacol Res 75: 3-14.

179. Horie T, Baba O, Kuwabara Y, Chujo Y, Watanabe S, et al. (2012) MicroRNA-33 deficiency reduces the progression of atherosclerotic plaque in ApoE-/- mice. J Am Heart Assoc 1: e003376.

180. Marquart TJ, Wu J, Lusis AJ, Baldán Á (2013) Anti-miR-33 therapy does not alter the progression of atherosclerosis in low-density lipoprotein receptordeficient mice. Arterioscler Thromb Vasc Biol 33: 455-458.

181. Rotllan N, Ramírez CM, Aryal B, Esau CC, Fernández-Hernando C (2013) Therapeutic silencing of microRNA-33 inhibits the progression of atherosclerosis in Ldlr-/- mice--brief report. Arterioscler Thromb Vasc Biol 33 : 1973-1977.

182. Horie T, Nishino T, Baba O, Kuwabara Y, Nakao T, et al. (2013) MicroRNA-33 regulates sterol regulatory element-binding protein 1 expression in mice. Nat Commun 4: 2883

183. Goedeke L, Salerno A, Ramirez CM, Guo L, Allen RM, et al. (2014) Long term therapeutic silencing of miR 33increases circulating triglyceride levels and hepatic lipid accumulation in mice. EMBO Mol Med 6: 1133-1141.

184.Ge Q, Brichard S, Yi X, Li Q (2014) microRNAs as a new mechanism regulating adipose tissue inflammation in obesity and as a novel therapeutic strategy in the metabolic syndrome. J Immunol Res 2014: 987285.

185. Chang RC, Ying W, Bazer FW, Zhou B (2014) MicroRNAs Control Macrophage Formation and Activation: The Inflammatory Link between Obesity and Cardiovascular Diseases. Cells 3: 702-712.

186. Muthiah M, Islam MA, Lee HJ, Moon MJ, Cho CS, et al. (2015) MicroRNA delivery with osmotic polysorbitol-based transporter suppresses breast cancer cell proliferation. Int J Biol Macromol 72: 1237-1243. 
Citation: Kaur KK, Allahbadia GN, Singh M (2015) An Update on Microrna's and Metabolic Regulation with Future Therapeutic PotentialsRegarding Diagnosis and Treatment of Obesity, Metabolic Syndrome and Other Related Disorders. J Health Med Informat 6: 184. doi: $10.4172 / 2157-7420.1000184$

187. Burnett JC, Rossi JJ (2012) RNA-based therapeutics: current progress and future prospects. Chem Biol 19: 60-71.

188. Frank-Kamenetsky M, Grefhorst A, Anderson NN, Racie TS, Bramlage B, et al. (2008) Therapeutic RNAi targeting PCSK9 acutely lowers plasma cholesterol in rodents and LDL cholesterol in nonhuman primates. Proc Natl Acad Sci U S A 105: 11915-11920.
189.Prabhu RH, Patravale VB, Joshi MD (2015) Polymeric nanoparticles for targeted treatment in oncology: current insights. Int J Nanomedicine 10: 1001 1018 